Research Article

\title{
Modelling and Dynamic Analysis of the Spiral Bevel Gear-Shaft-Bearing-Gearbox Coupling System
}

\author{
Haimin Zhu $\mathbb{D}^{1},{ }^{1}$ Weifang Chen ${ }^{D},{ }^{1}$ Rupeng Zhu ${ }^{D},{ }^{1}$ Jie Gao, ${ }^{2}$ and Meijun Liao ${ }^{2}$ \\ ${ }^{1}$ National Key Laboratory of Science and Technology on Helicopter Transmission, \\ Nanjing University of Aeronautics and Astronautics, Nanjing 210016, China \\ ${ }^{2}$ AECC Hunan Aviation Powerplant Research Institute, Zhuzhou 412000, China \\ Correspondence should be addressed to Weifang Chen; meewfchen@nuaa.edu.cn
}

Received 6 May 2019; Accepted 28 July 2019; Published 8 September 2019

Academic Editor: Renato Vidoni

Copyright ( $\odot 2019$ Haimin Zhu et al. This is an open access article distributed under the Creative Commons Attribution License, which permits unrestricted use, distribution, and reproduction in any medium, provided the original work is properly cited.

To accurately study the dynamic characteristics of the spiral bevel gear transmission system in a helicopter tail transmission system, the finite element model of the gear shaft was established by a Timoshenko beam element, and the mechanical model of the spiral bevel gear was created by the lumped mass method. The substructure method is employed to extract the dynamic parameters from the gearbox's finite element model, and the dynamic model of the spiral bevel gear-shaft-bearing-gearbox coupling system was built according to the interface coordination conditions. In the model, the influences of time-varying stiffness, a timevarying transmission error, gearbox flexibility, unbalance excitation, and a flexible shaft and bearing support on the system vibration were taken into account simultaneously. On this basis, the dynamic differential equations of the full coupling system of the spiral bevel gear were derived, and the effects of the gearbox flexibility, the shaft angle, and the unbalance on the dynamic properties of the system were analysed. The results show that the gearbox flexibility can reduce the gear meshing force and bearing force, in which there is a more significant impact on the bearing force. The shaft angle affects the position, size, and direction of the system's axis trajectory. Meanwhile, the meshing force and the bearing force of the system are also varied because of the various pitch angles of the driving and driven gears under different shaft angles. The unbalance of the gear shaft has an effect on the vibration of the spiral bevel gear transmission system in all directions, wherein the influence on the torsional vibration is the most significant, and the influence increases as the unbalance rises. The unbalance of the gear shaft also affects the meshing force and bearing force, which increases as the rotational speed rises. This research provides a theoretical basis to optimize dynamic performance and reduce the vibration and noise of a spiral bevel gear full coupling system.

\section{Introduction}

The spiral bevel gear has the characteristics of the firm bearing capacity, a large coincidence degree, and stable operation. Its noise and vibration are relatively small during high-speed operations, and it is widely used in the core transmission systems of helicopters and ships. The most common form of the spiral bevel gear transmission system is the orthogonal shaft system. Because of the limitations of space and shape, the nonorthogonal spiral bevel gear is widely employed in helicopter tail transmission systems, in which the shaft angle is not 90, resulting in the vibration behaviours of the gear pair and the rotor system varying accordingly. In addition, the stiffness of the gearbox is relatively high in general, so the influence of the gearbox flexibility can be ignored when studying the dynamic characteristics of the gear system. However, the wall thickness of the helicopter gearbox is comparatively thin, and the flexible support brought by the thin-wall structure of the gearbox causes a dynamic coupling effect between the gear transmission system and the gearbox. Therefore, in order to obtain more accurate system response and better predict the vibrational noise of such systems, it is necessary to establish a nonorthogonal spiral bevel gear-shaft-bearing- box coupling mechanical model to analyse the dynamic properties of the system.

Currently, the dynamics of the spiral bevel gear transmission system has been studied extensively, both domestically and internationally. Wang et al. [1] established a nonlinear vibration equation for the bending-torsional- 
axial coupling vibration of a 7-degrees-of-freedom spiral bevel gear. The torsional, lateral, and axial vibration displacements and velocities of the spiral bevel gear system under various working conditions are obtained by the operator algorithm. The results show that with the variety of the meshing frequency, the system enters into chaos through period-doubling bifurcation; with the variety of the support stiffness, the system changes into chaos through quasi-period bifurcation; and in the process of the meshing frequency varying, jump phenomena exist in the system. Feng and Song [2] considered the time-varying meshing force of the gear, the position of the meshing point, the transmission error, the direction of the friction force, and the friction coefficient, and then established a dynamic model of concentrated parameters. On this basis, the effects of the dynamic meshing force and dynamic transmission error on the system response are investigated. Wang et al. [3] analysed the torsional vibration of the spiral bevel gear transmission system with backlash and timevarying meshing stiffness. The results showed that when the gear system reciprocates, the backlash and time-varying meshing stiffness will produce a coupling effect, causing the gear system to show obvious nonlinear characteristics. The internal excitation frequency, the meshing stiffness amplitude, the initial condition, and the damping ratio all have an essential impact on the system's dynamic features. The variation of each parameter makes the system's response appear in harmonic period solution and chaotic solution. Tang et al. [4], considering such influencing factors as the time-varying meshing stiffness and gear clearance, analysed the effect of the static transmission error on the nonlinear dynamic response of a spiral bevel gear system. The dynamic response, bifurcation diagram, time domain response, phase diagram, and Poincaré map are all obtained by solving the dynamic equations. Fan et al. [5] examined the linear dynamics of the transmission system of a nonorthogonal spiral bevel gear and analysed the system's inherent characteristics, steady-state response, and axial trajectory. Cheng and Lim [6] built a three-dimensional multi-degrees-of-freedom model of the hypoid gear and analysed the dynamic coupling and vibrational response sensitivity using the response function of the meshing force. Then, the influences of the system parameters on the dynamic response of the hypoid gear were studied, and it was proven that the design parameters and working conditions have significant impacts on the modal and vibration response. Yang and Lim [7] considered the nonlinear clearance and time-varying meshing stiffness and solved the dynamic meshing force and vibration response by the variable step size Runge-Kutta method. The analysis showed that damping could dramatically reduce the dynamic meshing force. Wang et al. [8] established a hypoid gear dynamics model with a time-varying meshing force considering the effect of the nonlinear clearance and studied the impact of the different meshing waveforms on the dynamic response of gear dynamics. Xu et al. $[9,10]$ constructed the bending-torsion-axial coupling dynamic model of the multi-freedom spiral bevel gear through the lumped mass method and then studied the chaotic and bifurcation properties of the system. Yassine et al. [11] constructed a dynamic model of a two-stage bevel gear transmission system, mainly considering the effect of the time-varying meshing stiffness. The Newmark numerical algorithm was utilised to solve the equations, and the dynamic features of the system were analysed in the time domain and the frequency domain. Peng [12] created a multibody dynamic model of hypoid gears and studied the effects of misalignment, torque, and eccentricity on the dynamic response of the system. Li et al. [13] investigated the effect of an asymmetric time-varying meshing stiffness on the spiral bevel gear transmission system. It was determined that the meshing stiffness has a higher impact on the driving side than that on the driven side. Under a light load, the rise in the meshing stiffness on the drive side deteriorates the vibration stability of the transmission system. Wu and Yang [14] utilised the extended transfer matrix method to analyse the bending-torsional-coupled vibration of the multi-degrees-of-freedom damped shafting caused by external excitation. It was shown that the natural frequency of bending-torsion coupling is close to the natural frequency of torsion. Choi and Mau [15] analysed the dynamic behaviours of the gear-coupled rotor system by using the transfer matrix method. The Timoshenko beam element was employed to model the rotating shaft, and the natural frequency and vibration mode were acquired by studying the bending-torsion-coupled vibration of the system. Neriya et al. [16] adopted the finite element method to simulate the bending-torsion coupling vibration of the gear system comparatively early. The finite element method has been widely utilized by scholars both domestically and abroad because this method can better simulate the influence of a flexible shaft and the bearing parameters on the dynamic response of the gear pair [17-20]. $\mathrm{Li}$ and $\mathrm{Hu}$ [21] discussed the linear dynamic properties of the bending-torsional coupling of the rotorbearing system with spiral bevel gears via the finite element method after considering the generalized meshing relationship between the conical teeth. Hua et al. [22] employed the finite element method and the lumped parameter method to analyse the dynamics of the spiral bevel gear-rotor system. Yavuz et al. [23], aking the backlash, time-varying meshing stiffness, and the transmission error into account, built a dynamic model of the spiral bevel gear based on the finite element method, solved differential equations using the harmonic balance method, and studied the effects of backlash, time-varying meshing stiffness, and a bearing stiffness on the system dynamics. Choy et al. $[24,25]$ examined the effect of the housing's vibration on the dynamic features of the parallel shaft gear transmission system via the modal synthesis method, but the gearbox was simplified dramatically. Ren et al. [26] established the gear-shaft-bearing-box coupling dynamic model of the parallel shaft via the impedance synthesis method, taking the dynamical coupling between the transmission system and the housing into consideration, and investigated the influence factor of the natural frequency, meshing force, and bearing force. According to the literature retrieved, the modelling methods of the gear transmission system's 
dynamics mainly contain the lumped mass method, the transfer matrix method, and the finite element method. Among them, the finite element method not only considers the influence of the shaft flexibility and bearing support but also conveniently couple the forces in the surrounding environment, which is especially suitable for the complex geared rotor coupling systems. Currently, the application of the finite element method is very mature for gear systems with parallel shafts, such as spur gears and helical gears. However, there have been relatively few research works on spiral bevel gear systems with nonparallel shafts, and the effect of thin-walled gearbox flexibility on the dynamics of the transmission system has not been taken into account.

In this article, a nonorthogonal spiral bevel gear transmission system supported by a thin-walled gearbox is taken as the research object. First, analysis of the transient dynamics is carried out using finite element software to obtain the timevarying meshing stiffness of the spiral bevel gear pair because the tooth surface of the spiral bevel gear is a complex curved surface. Then, the dynamic equation of the nonorthogonal spiral bevel gear transmission system is constructed via the finite element method and the lumped mass hybrid modelling method. The dynamic parameters of the gearbox system are extracted by the substructure method and are connected by the nodes of the bearing support, thus establishing the dynamic model of the spiral bevel gear-shaft-bearing-box coupling system. On this basis, the dynamic equations of the whole coupling system are solved using the Newmark numerical algorithm, and the effects of the gearbox flexibility, the shaft angle, and the shaft's unbalance value on the dynamic properties of the coupling system are analysed.

\section{Mechanical Model of the Spiral Bevel Gear Full Coupling System}

The spiral bevel gear full coupling system is a gear-shaftbearing-box system, which is divided into two parts: the spiral bevel gear transmission system and the gearbox system. As shown in Figure 1, it contains a hollow input shaft, a hollow output shaft, a pair of nonorthogonal spiral bevel gears, four ball bearings, and a gearbox connected with the gear transmission system. The coordinates $O-X Y Z$ in Figure 1 are the global coordinate of the entire coupling system.

The three-dimensional model of the system is simplified, and a mechanical model of the full coupling transmission system of the spiral bevel gear is constructed. Because of the distinct angle between the driven gear shaft and the driving gear shaft, the vibration displacements of the driven gear and its rotating shaft need to be converted to the global coordinate system through a coordinate transform. The mechanical model of the full coupling system of the spiral bevel gear includes the flexible rotating shaft unit, the meshing unit, the bearing support unit, and the gearbox unit. First, the nodes of the beam elements are divided along the axis at the abrupt change of the shaft section, the bearing support, the gear meshing point, the power point, etc. The gearbox system, because of its complex structure, is more difficult to model directly using the finite element method. The substructure method is employed to convert the dynamic parameters of the box element to the connection node of the bearing support, and the bearing element is applied to connect the gearbox node and the rotating shaft node at the bearing position. Then the finite element method is utilised to assemble each element matrix, and the overall motion equation of the system with the displacement of each node as a generalized coordinate can be obtained. Through the above analysis, the vibration problem of a full coupling system of spiral bevel gears with a continuous mass distribution can be reduced to a vibration problem of a system with limited degrees-of-freedom. Figure 2 shows the mechanical model of a full coupling system of the nonorthogonal spiral bevel gear, in which nodes 1-9 are the nodes corresponding to the driving shaft's beam element, nodes 10-18 are the nodes corresponding to the beam element of the driven axle, and nodes 19-22 are the nodes of the gearbox unit acquired by the substructure method.

\section{Dynamic Equation of the Spiral Bevel Gear Full Coupling System}

3.1. Calculation of the Meshing Stiffness of the Spiral Bevel Gear. The gear's meshing stiffness refers to the synthetic effect of each pair of gear teeth involved in meshing during the meshing process. It is difficult to calculate the meshing stiffness of the gear teeth using the theoretical analysis method because the tooth surface of the spiral bevel gear is a space meshing gear. Meanwhile, the tooth thickness is variable. Therefore, this study utilises finite element software to perform dynamic analysis and obtain an accurate meshing stiffness.

The comprehensive elastic deformation $\delta n$ and contact force $F_{n}$ are calculated when multiple pairs of gears mesh at the same time, and then the comprehensive meshing stiffness can be obtained directly. The comprehensive elastic deformation of the gear teeth includes the contact elastic deformation due to the local Hertz contact $\delta H$, the displacement of the contact position of the gear teeth caused by bending of the gear teeth $\delta b$, and the deformation of the bearings, shafts, and supporting structures on the contact positions $\delta f$. The deformation of the bearings, shafts, and supporting structures has a relatively small influence on the meshing stiffness. Therefore, this study only takes $\delta H$ and $\delta b$ into account, so the deformation of the gear at a certain moment can be expressed as follows: $\delta n=\sum_{i=1}^{2} \delta H_{i}+\sum_{i=1}^{2} \delta b_{i}$.

First, the gear's meshing period is divided into $n$ segments, and the meshing stiffness at each time point $K_{i}(i=$ $1,2,3, \ldots, n)$ is calculated $[27,28]$. Then, a Fourier transform is utilized to convert a series of discrete values $K_{i}$ into a meshing stiffness's curve. In this article, the main parameters of the nonorthogonal spiral bevel gear are shown in Table 1, and then the comprehensive meshing stiffness is analysed. In order to improve the efficiency of calculation, nine pairs of gear teeth are selected from the spiral bevel gear pair for the meshing analysis. Figure 3 shows the finite element analysis of the meshing stiffness of the spiral bevel gear, including the meshing of the gear pair and the contact analysis of gear pair.

Each period $T$ is divided into ten segments on average, and two meshing periods are taken. Then, each $K_{i}$ value at its 


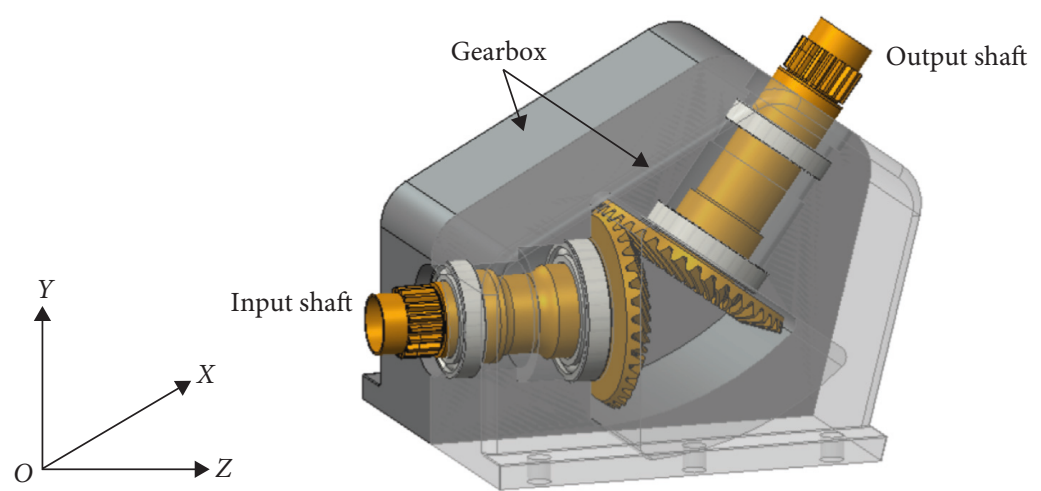

(a)

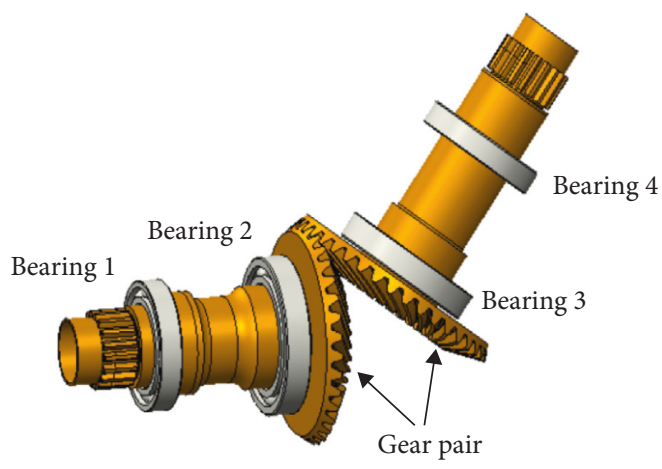

(b)

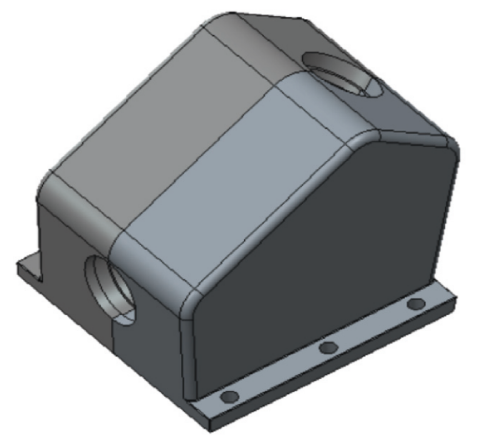

(c)

Figure 1: Full coupling system of the spiral bevel gear. (a) The three-dimensional model of the spiral bevel gear fully coupled transmission system. (b) Gear transmission system. (c) Gearbox system.

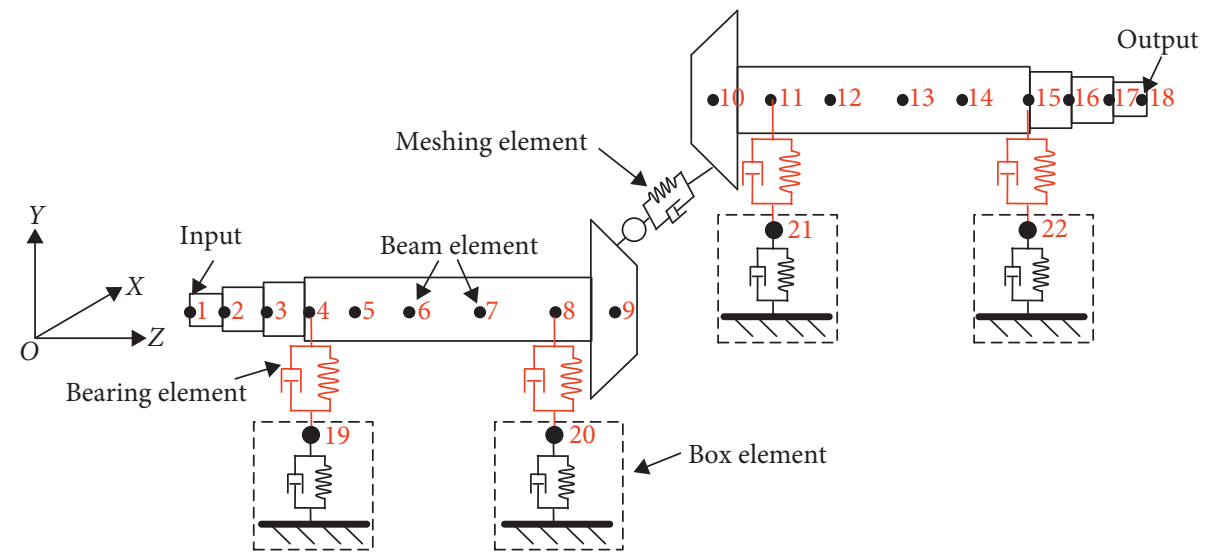

FIGURE 2: Mechanical model of the nonorthogonal spiral bevel gear fully coupled transmission system.

corresponding time $t_{i}$ is calculated. By performing a Fourier transform on a series of discrete stiffness values obtained from the finite element analysis, a stiffness curve expression can be obtained, and the stiffness is transformed into the following form:

$$
k_{\mathrm{h}}(t)=k_{\mathrm{m}}+\sum_{i=1}^{N}\left[A_{i} \cos \left(i \Omega_{\mathrm{h}} t\right)+B_{i} \sin \left(i \Omega_{\mathrm{h}} t\right)\right],
$$

where $k_{\mathrm{m}}$ is the average value of the time-varying meshing stiffness, $A_{i}, B_{i}$ is the $i$ th-order harmonic amplitude of the time-varying meshing stiffness, $\Omega_{\mathrm{h}}$ is the excitation frequency, and $N$ represents the order of the Fourier series, and the series was truncated at $N=7$ in this article.

Figure 4 shows a graph depicting the comprehensive meshing stiffness of the spiral bevel gear transmission during the two meshing cycles.

3.2. Gear Transmission System. The gear transmission system includes the flexible shaft unit, spiral bevel gear meshing unit, and the bearing unit, which are analysed below. 
TABLE 1: Main design parameters of the pinion and gear.

\begin{tabular}{lcc}
\hline & Pinion & Gear \\
\hline Young's modulus $(\mathrm{Pa})$ & $E=2.1 \mathrm{e} 9$ \\
Poisson's ratio & $N=0.3$ \\
Pressure angle $\left(^{\circ}\right)$ & 22.5 \\
Spiral angle $\left(^{\circ}\right)$ & 35 \\
Transverse module $(\mathrm{mm})$ & $m=5.6$ \\
Width of teeth $(\mathrm{mm})$ & $B=33$ \\
Shaft angle $\left(^{\circ}\right)$ & 126 \\
Damping ratio & $\xi=0.05$ \\
Mean of the transmission error $(\mathrm{m})$ & $e_{\mathrm{m}}=2 \times 10^{-5}$ \\
Amplitude of the transmission error $(\mathrm{m})$ & $e_{\mathrm{r}}=3 \times 10^{-5}$ \\
Pitch radius $(\mathrm{mm})$ & 72.5 & 87.6 \\
Number of teeth & $N_{1}=29$ & $N_{2}=35$ \\
Hand & Right & Left \\
\hline
\end{tabular}

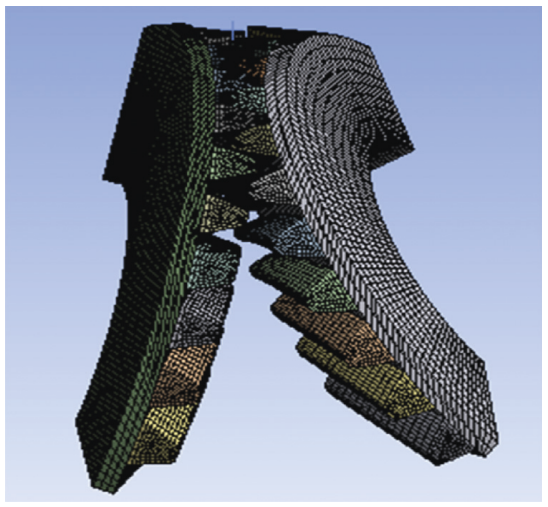

(a)

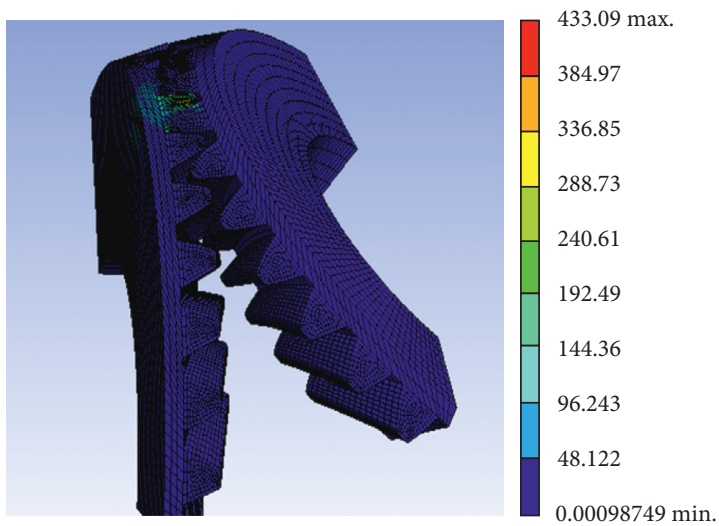

(b)

Figure 3: Finite element analysis of the meshing stiffness of the spiral bevel gear pair. (a) The meshing of the gear pairs. (b) Contact analysis of the gear pairs.

3.2.1. Flexible Shaft Unit. The gear shaft's finite element model is established by the Timoshenko beam element, taking the shear deformation, gyro moment, and moment of inertia into account, as shown in Figure 5, which gives the local coordinate of the beam element. In this article, each node has six degrees-of-freedom, i.e., the movement along the $X, Y$, and $Z$ directions and the rotation angle around the $X, Y$, and $Z$ directions. The element node's displacement

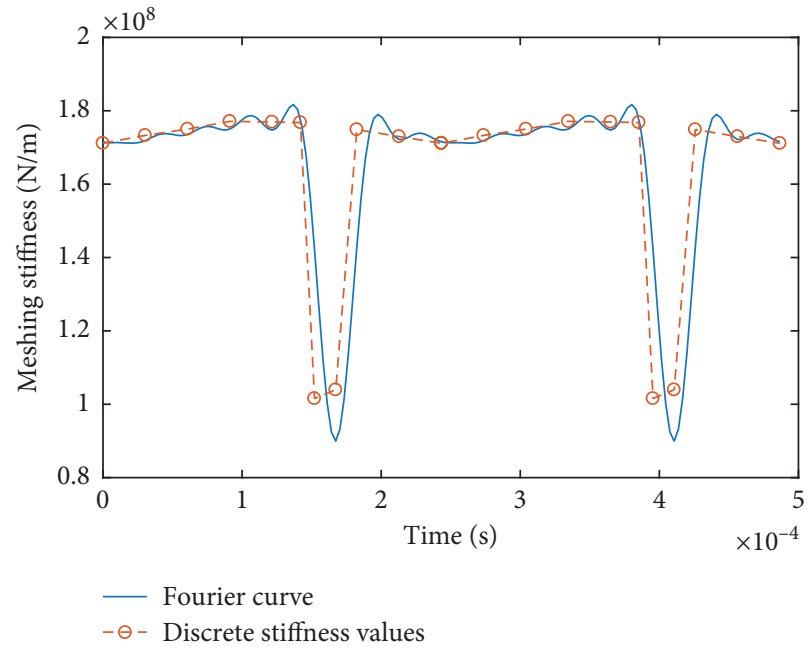

Figure 4: Curve of the comprehensive meshing stiffness of the spiral bevel gear transmission for two meshing cycles.

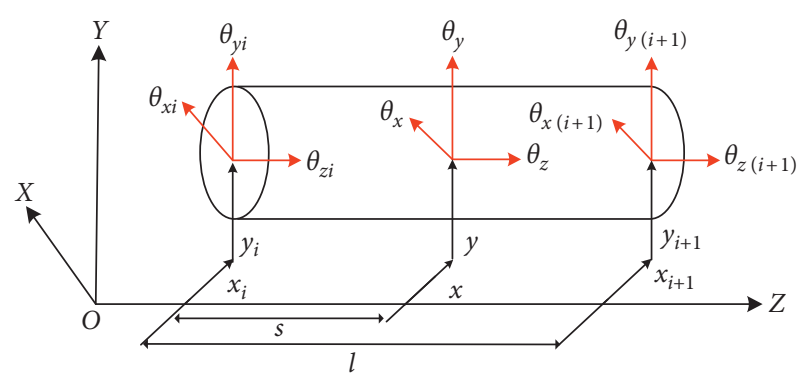

Figure 5: Local coordinate of the beam element.

vector includes 12 degrees-of-freedom, which can be expressed as follows:

$$
X_{\mathrm{e}}=\left[\begin{array}{llllllllllll}
x_{i} & y_{i} & z_{i} & \theta_{x_{i}} & \theta_{y_{i}} & \theta_{z_{i}} & x_{i+1} & y_{i+1} & z_{i+1} & \theta_{x_{(i+1)}} & \theta_{y_{(i+1)}} & \theta_{z_{(i+1)}}
\end{array}\right]^{\mathrm{T}} \text {. }
$$

According to the literature $[29,30]$, the mass matrix $\mathbf{M}_{\mathrm{e}}$, the stiffness matrix $\mathbf{K}_{\mathrm{e}}$, and the gyro matrix $\mathbf{G}_{\mathrm{e}}$ of the beam elements can be obtained.

It is noted that the directions of the local coordinate systems of the beam elements are various in the nonparallel shaft gear system. The beam element in the local coordinate needs to be transformed by the spatial coordinate to the global coordinate system. The relationship of the displacement of the $i$ th beam element node in the local coordinate system and its movement in the global coordinate system can be written as follows:

$$
\begin{aligned}
& \left\{x_{i}^{\prime}, y_{i}^{\prime}, z_{i}^{\prime}, \theta_{x_{i}}^{\prime}, \theta_{y_{i}}^{\prime}, \theta_{z_{i}}^{\prime}, x_{i+1}^{\prime}, y_{i+1}^{\prime}, z_{i+1}^{\prime}, \theta_{x_{i+1}}{ }^{\prime}, \theta_{y_{i+1}}{ }^{\prime}, \theta_{z_{i+1}}{ }^{\prime}\right\}^{\mathrm{T}} \\
& =[\lambda]\left\{x_{i}, y_{i}, z_{i}, \theta_{x_{i}}, \theta_{y_{i}}, \theta_{z_{i}}, x_{i+1}, y_{i+1}, z_{i+1}, \theta_{x_{i+1}}, \theta_{y_{i+1}}, \theta_{z_{i+1}}\right\}^{\mathrm{T}},
\end{aligned}
$$

where $\lambda=\operatorname{diag}[\mathbf{T} ; \mathbf{T} ; \mathbf{T} ; \mathbf{T}]$ and $\mathbf{T}=\mathbf{T}_{\gamma} \mathbf{T}_{\beta} \mathbf{T}_{\alpha}$, in which $\alpha, \beta$, and $\gamma$ are the rotation angles of the counterclockwise coordinate axis surrounding the global coordinate system 
$X, Y$, and $Z . \mathbf{T}_{\gamma}, \mathbf{T}_{\beta}$, and $\mathbf{T}_{\alpha}$ are projection vectors along $X$, $Y$, and $Z$, respectively, and can be given by the following equations:

$$
\begin{aligned}
& \mathbf{T}_{\alpha}=\left[\begin{array}{ccc}
1 & 0 & 0 \\
0 & \cos \alpha & \sin \alpha \\
0 & -\sin \alpha & \cos \alpha
\end{array}\right], \\
& \mathbf{T}_{\beta}=\left[\begin{array}{ccc}
\cos \beta & 0 & \sin \beta \\
0 & 1 & 0 \\
-\sin \beta & 0 & \cos \beta
\end{array}\right], \\
& \mathbf{T}_{\gamma}=\left[\begin{array}{ccc}
\cos \gamma & \sin \gamma & 0 \\
-\sin \gamma & \cos \gamma & 0 \\
0 & 0 & 1
\end{array}\right] .
\end{aligned}
$$

Substituting the coordinate transformation matrix (4) into formula (5), the mass matrix, the stiffness matrix, and the gyro matrix of the $i$ th beam element node in the global coordinate system are calculated, which can be described as follows:

$$
\begin{aligned}
& \mathbf{M}_{\mathrm{e}}^{\prime}=\mathbf{R}^{\mathrm{T}} \mathbf{M}_{\mathrm{e}} \mathbf{R}, \\
& \mathbf{K}_{\mathrm{e}}^{\prime}=\mathbf{R}^{\mathrm{T}} \mathbf{K}_{\mathrm{e}} \mathbf{R}, \\
& \mathbf{G}_{\mathrm{e}}^{\prime}=\mathbf{R}^{\mathrm{T}} \mathbf{G}_{\mathrm{e}} \mathbf{R} .
\end{aligned}
$$

The matrices of each element of the gear shaft, namely, $\mathbf{M}_{\mathrm{e}}^{\prime}$, $\mathbf{K}_{\mathrm{e}}^{\prime}$, and $\mathbf{G}_{\mathrm{e}}^{\prime}$, in the global coordinate system are assembled to obtain the mass matrix of the overall gear shaft $\left[\mathbf{M}_{\mathrm{r}}\right]$, the stiffness matrix of the overall gear shaft $\left[\mathbf{K}_{\mathrm{r}}\right]$, and the gyro matrix of the overall gear shaft $\left[\mathbf{G}_{\mathrm{r}}\right]$, respectively.

The damping of the gear shaft is calculated via Rayleigh damping, i.e., $\left[\mathbf{C}_{\mathrm{r}}\right]=\alpha\left[\mathbf{M}_{\mathrm{r}}\right]+\beta\left[\mathbf{K}_{\mathrm{r}}\right]$, in which $\alpha$ and $\beta$ are the mass damping coefficient and stiffness damping coefficient, respectively, which are calculated from the following equations:

$$
\begin{aligned}
& \alpha=\frac{2 \omega_{1} \omega_{2}\left(\xi_{1} \omega_{2}-\xi_{2} \omega_{1}\right)}{\left(\omega_{2}^{2}-\omega_{1}^{2}\right)}, \\
& \beta=\frac{2\left(\xi_{2} \omega_{2}-\xi_{1} \omega_{1}\right)}{\omega_{2}^{2}-\omega_{1}^{2}}
\end{aligned}
$$

where $\xi_{1}$ and $\xi_{2}$ denote the first and second mode damping ratios, respectively, generally supposing that $\xi_{1}=0.005$ and $\xi_{2}=0.01 . \omega_{1}$ and $\omega_{2}$ are the first- and second-order natural frequencies of the rotor system, respectively, which can be obtained through modal experiments.

When each element matrix of the gear shaft is acquired, the motion differential equation of a single gear shaft can also be obtained:

$$
\mathbf{M}_{\mathrm{r}} \ddot{\mathbf{X}}+\left(\mathbf{C}_{\mathrm{r}}+\omega \mathbf{G}_{\mathrm{r}}\right) \dot{\mathbf{X}}+\mathbf{K}_{\mathrm{r}} \mathbf{X}=0
$$

3.2.2. Meshing Unit. The schematic diagram of the dynamical model of the nonorthogonal spiral bevel gear is shown in Figure 6. In this model, the local coordinate systems of the pinion and gear are fixed at the center of the two gears, namely, $O_{p}-X_{p} Y_{p} Z_{p}$ and $O_{g}-X_{g} Y_{g} Z_{g}$, respectively. The direction of the local coordinate system of the driving gear is consistent with that of the global coordinate system. The dynamic model of the meshing unit is built based on the lumped mass method, and the lumped mass and the concentrated moment of inertia are utilised to simulate two spiral bevel gears. The model simulates the coupling effect during the meshing process through a timevarying meshing stiffness $K_{\mathrm{h}}(t)$, a meshing damping $c_{\mathrm{m}}$, and a transmission error $e(t)$, without taking the backlash clearance, meshing friction force, and gear meshing position into consideration. The bending-torsion-shaft-pendulum coupling vibration of the two gears is considered so that the 12-degrees-offreedom spiral bevel gear meshing unit can be obtained, namely, $\left\{x_{p}, y_{p}, z_{p}, \theta_{p x}, \theta_{p y}, \theta_{p z}, x_{q}, y_{q}, z_{q}, \theta_{q x}, \theta_{q y}, \theta_{q z}\right\}$.

The spiral bevel gear is a space meshing gear, and the relative displacement of the two gears along the meshing line direction is difficult to obtain directly. By rotating the local coordinate systems of the pinion and gear and performing multiple coordinate projections, the relative displacement of the meshing direction of the spiral bevel gear can be transformed into that of the virtual spur gear's meshing direction. The transformation process of the relative displacement of the spiral bevel gear in the direction of the meshing line is shown in Figure 7.

The directional cosine vector of the pinion and gear $\mathbf{n}_{i}$ $(i=p, q)$ can be calculated with a series of coordinate transformation as follows:

$$
\mathbf{n}_{i}=\left[n_{i x}, n_{i y}, n_{i z}\right]=\left[\begin{array}{l}
1 \\
0 \\
0
\end{array}\right]^{\mathrm{T}} \mathbf{T}_{i z} \mathbf{T}_{i y} \mathbf{T}_{i x}, \quad i=p, g,
$$

where $\mathbf{T}_{i x}, \mathbf{T}_{i y}$, and $\mathbf{T}_{i z}$ indicate the transformation matrix about the $x, y$, and $z$ axes, respectively, and can be expressed as follows:

$$
\begin{aligned}
T_{i x} & =\left[\begin{array}{ccc}
1 & 0 & 0 \\
0 & \cos \delta_{i} & \sin \delta_{i} \\
0 & -\sin \delta_{i} & \cos \delta_{i}
\end{array}\right], \\
T_{i y} & =\left[\begin{array}{ccc}
\cos \left(-\beta_{i}\right) & 0 & \sin \left(-\beta_{i}\right) \\
0 & 1 & 0 \\
-\sin \left(-\beta_{i}\right) & 0 & \cos \left(-\beta_{i}\right)
\end{array}\right], \\
T_{i z}= & {\left[\begin{array}{ccc}
\cos (p i-\alpha) & \sin (p i-\alpha) & 0 \\
-\sin (p i-\alpha) & \cos (p i-\alpha) & 0 \\
0 & 0 & 1
\end{array}\right], }
\end{aligned}
$$

where $\delta_{i}=\delta_{1}$ and $p i-\delta_{2}(i=p, q)$ represent the angles of the pinion and gear rotating in the direction of the pitch angles, respectively. $\beta_{i}=\beta$ and $-\beta(i=p, q)$ are the midspiral angles of the gears, and $\alpha$ denotes the pressure angle.

The directional rotation radii of the meshing force, which can be written as follows:

$$
\left\{\begin{array}{l}
\lambda_{i x}=\mathbf{n}_{i} \cdot\left(\mathbf{u}_{i x} \times \mathbf{r}_{i}\right)=r_{i y} n_{i z}-r_{i z} n_{i y} \\
\lambda_{i y}=\mathbf{n}_{i} \cdot\left(\mathbf{u}_{i y} \times \mathbf{r}_{i}\right)=r_{i z} n_{i x}-r_{i x} n_{i z} \\
\lambda_{i z}=\mathbf{n}_{i} \cdot\left(\mathbf{u}_{i z} \times \mathbf{r}_{i}\right)=r_{i x} n_{i y}-r_{i y} n_{i x}
\end{array}\right.
$$




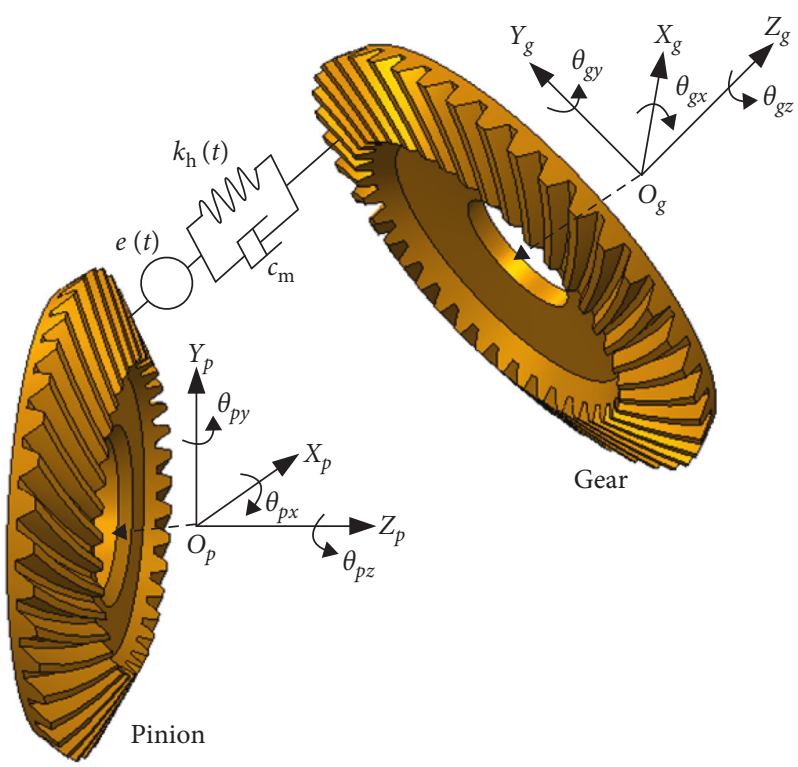

Figure 6: Schematic diagram of the dynamical model of the nonorthogonal spiral bevel gear.

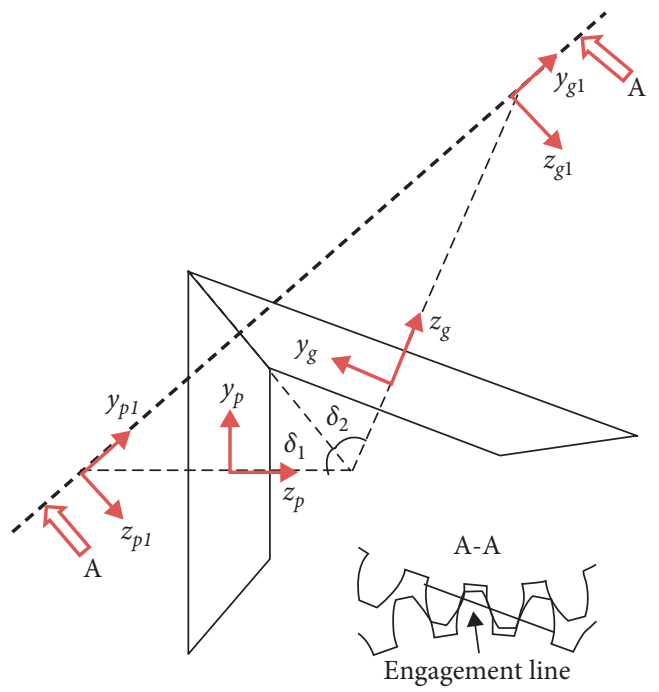

(a)

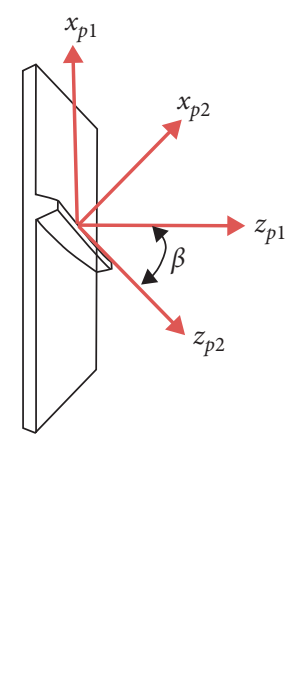

(b)

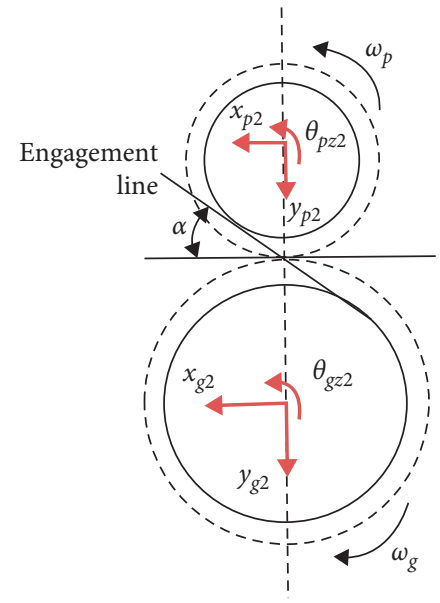

(c)

Figure 7: Transformation process of the relative displacement of a spiral bevel gear in the direction of the meshing line. (a) Projection along the pitch angle direction. (b) Projection along the spiral angle direction. (c) Projection along the pressure angle direction.

where $\mathbf{r}_{i}=\left[\begin{array}{lll}r_{i x} & r_{i y} & r_{i z}\end{array}\right]^{\mathrm{T}}$ represents the equivalent position vector of the meshing point, (this article ignores the variety of the meshing point's position). Referring to Figure 6, the equivalent position vectors of the corresponding meshing point of the pinion and the gear are $\mathbf{r}_{p}=\left[\begin{array}{lll}0 & r_{p} & 0\end{array}\right]^{\mathrm{T}}$ and $\mathbf{r}_{g}=\left[\begin{array}{lll}0 & r_{g} & 0\end{array}\right]^{\mathrm{T}}$, respectively, in which $r_{p}$ and $r_{g}$ are the pitch radii of the pinion and gear at the midpoint of the tooth width, respectively. $\mathbf{u}_{x i}=\left[\begin{array}{lll}1 & 0 & 0\end{array}\right]^{\mathrm{T}}, \mathbf{u}_{y i}=\left[\begin{array}{lll}0 & 1 & 0\end{array}\right]^{\mathrm{T}}$, and $\mathbf{u}_{z i}=\left[\begin{array}{lll}0 & 0 & 1\end{array}\right]^{\mathrm{T}}$ are the unit vectors in the $X, Y$, and $Z$ directions, respectively. In the above equation, $i=p, g$ represents the pinion and the gear, respectively.
Also, the relative displacement of the spiral bevel gear on the meshing line can be expressed as follows:

$$
X_{n}=\mathbf{V X}_{\mathrm{m}}-e_{n}(t)
$$

where $\mathbf{V}=\left[n_{p x}, n_{p y}, n_{p z}, \lambda_{p x}, \lambda_{p y}, \lambda_{p z},-n_{g x},-n_{g y},-n_{g z}, \lambda_{g x}\right.$, $\left.\lambda_{g y}, \lambda_{g z}\right]$ is the projection vector for the displacement of the spiral bevel gear in all directions to the meshing line; $\mathbf{X}_{\mathrm{m}}=$ $\left[x_{p}, y_{p}, z_{p}, \theta_{p x}, \theta_{p y}, \theta_{p z}, x_{g}, y_{g}, z_{g}, \theta_{g x}, \theta_{g y}, \theta_{g z}\right]^{\mathrm{T}}$ represents the displacement vector of the spiral bevel gear; $e_{n}(t)=e_{\mathrm{m}}+e_{\mathrm{r}} \sin (\Omega t+\phi)$, in which $e_{\mathrm{m}}$ and $e_{\mathrm{r}}$ represent the average value and the amplitude of the transmission error, respectively; $\Omega$ indicates the gear meshing's angular 
frequency; and $\phi$ represents the initial phase angle of the engagement.

Combined with the meshing stiffness and relative displacement of the spiral bevel gear obtained, the meshing force of the spiral bevel gear pair can be acquired by the following equation:

$$
F_{n}=k_{\mathrm{h}}(t) X_{n}+c_{\mathrm{m}} \dot{X}_{n}
$$

where $c_{\mathrm{m}}$ represents the meshing damping, which can be calculated by the following:

$$
c_{\mathrm{m}}=2 \xi \sqrt{k_{\mathrm{m}}\left(\frac{1}{m_{\mathrm{eq}, p}}+\frac{1}{m_{\mathrm{eq}, g}}\right)},
$$

where $\xi$ is the meshing damping ratio, generally taken as $0.03 \sim 0.17 ; m_{\mathrm{eq}, i}=I_{z i} / r_{i}^{2}(i=p, g)$ denotes the equivalent mass of the gear.

According to Newton's second law, the dynamic equation of the spiral bevel gear meshing unit can be written as follows:

$$
\left\{\begin{array}{l}
m_{p} \ddot{x}_{p}=F_{n} n_{p x}+m_{p} e_{1} \Omega_{1}^{2} \cos \left(\Omega_{1} t\right), \\
m_{p} \ddot{y}_{p}=F_{n} n_{p y}+m_{p} e_{1} \Omega_{1}^{2} \sin \left(\Omega_{1} t\right), \\
m_{p} \ddot{z}_{p}=F_{n} n_{p z}, \\
I_{p} \ddot{\theta}_{p x}+J_{p} \Omega_{1} \dot{\theta}_{p y}=F_{n} \lambda_{p x}, \\
I_{p} \ddot{\theta}_{p y}-J_{p} \Omega_{1} \dot{\theta}_{p x}=F_{n} \lambda_{p y}, \\
J_{p} \ddot{\theta}_{p z}=F_{n} \lambda_{p z}, \\
m_{g} \ddot{x}_{g}=F_{n} n_{g x}+m_{g} e_{2} \Omega_{2}^{2} \cos \left(\Omega_{2} t\right), \\
m_{g} \ddot{y}_{g}=F_{n} n_{g y}+m_{g} e_{2} \Omega_{2}^{2} \sin \left(\Omega_{2} t\right), \\
m_{g} \ddot{z}_{g}=F_{n} n_{g z}, \\
I_{g} \ddot{\theta}_{g x}+J_{g} \Omega_{2} \dot{\theta}_{g y}=F_{n} \lambda_{g x}, \\
I_{g} \ddot{\theta}_{g y}-J_{g} \Omega_{2} \dot{\theta}_{g x}=F_{n} \lambda_{g y}, J_{g} \ddot{\theta}_{g z}=F_{n} \lambda_{g z},
\end{array}\right.
$$

where $m_{p}$ and $m_{g}$ represent the mass of the pinion and gear, respectively; $I_{p}$ and $I_{g}$ are the diameter rotational inertia of the pinion and gear, respectively; $J_{p}$ and $J_{g}$ represent the polar moment of inertia of the pinion and gear, respectively; $e_{1}$ and $e_{2}$ denote the pinion and gear's eccentricity, respectively; and $\Omega_{1}$ and $\Omega_{2}$ are the angular velocity of the pinion and gear, respectively.

Substituting formula (14) into the equations in (15) and arranging the equations into a matrix form, the motion differential equations of the gear meshing unit can be obtained as follows:

$$
\begin{aligned}
& \mathbf{M}_{\mathrm{m}} \ddot{\mathbf{X}}_{\mathrm{m}}+\left(\mathbf{C}_{\mathrm{m}}+\left[\begin{array}{ll}
\Omega_{1} \mathbf{G}_{\mathrm{m} 1} & \\
& \Omega_{2} \mathbf{G}_{\mathrm{m} 2}
\end{array}\right]\right) \dot{\mathbf{X}}_{\mathrm{m}}+\mathbf{K}_{\mathrm{m}} \mathbf{X}_{\mathrm{m}} \\
& =\left(k_{\mathrm{m}}(t) e_{n}(t)+c_{\mathrm{m}} \dot{e}_{n}(t)\right) \mathbf{B}^{\mathrm{T}},
\end{aligned}
$$

where $\dot{e}_{n}(t)$ is the derivative of the comprehensive meshing error; $\mathbf{G}_{\mathrm{m} 1}$ and $\mathbf{G}_{\mathrm{m} 2}$ represent the gyro matrix of the pinion and the gear, respectively; and $\mathbf{M}_{\mathrm{m}}$ is the mass matrix of the meshing unit, which can be expressed as follows:
$\mathbf{M}_{\mathrm{m}}=\operatorname{diag}\left\{m_{p x}, m_{p y}, m_{p z}, I_{p x}, I_{p y}, I_{p z}, m_{q x}, m_{q y}, m_{q z}, I_{q x}, I_{q y}, I_{q z}\right\}$.

The stiffness matrix $\mathbf{K}_{\mathrm{m}}$ and the damping matrix $\mathbf{C}_{\mathrm{m}}$ of the meshing element in the global coordinate system can be calculated as follows:

$$
\begin{aligned}
\mathbf{K}_{\mathrm{m}} & =k_{\mathrm{m}} \mathbf{B}^{\mathrm{T}} \mathbf{B}, \\
\mathbf{C}_{\mathrm{m}} & =c_{\mathrm{m}} \mathbf{B}^{\mathrm{T}} \mathbf{B},
\end{aligned}
$$

where $\quad \mathbf{B}=\left[n_{p x}, n_{p y}, n_{p z}, \lambda_{p x}, \lambda_{p y}, \lambda_{p z},-n_{p x},-n_{p y},-n_{p z}\right.$, $\left.-\lambda_{p x},-\lambda_{p y},-\lambda_{p z}\right]^{\mathrm{T}}$.

3.2.3. Bearing Unit. The spiral bevel gear transmission system is supported by four angular contact ball bearings. During actual operation, there is a coupling relationship between the displacements of the bearings, and the stiffness in each direction varies with time. The time-varying stiffness of the bearings is usually not considered, and only the main stiffness term is retained, when calculating the dynamics of the gear system. The stiffness matrix of the ball bearing can be expressed as follows:

$$
\mathbf{K}_{b}=\operatorname{diag}\left[k_{x x}, k_{y y}, k_{z z}, k_{\theta x}, k_{\theta y}, 0\right] .
$$

The bearing damping takes the same form as the stiffness and can also be written as follows:

$$
\mathbf{C}_{b}=\operatorname{diag}\left[c_{x x}, c_{y y}, c_{z z}, c_{\theta x}, c_{\theta y}, 0\right] \text {. }
$$

According to Newton's second law, the dynamic differential equation of the bearing can be given as follows:

$$
\mathbf{M}_{e k} \ddot{\mathbf{X}}_{e k}+\mathbf{C}_{b}\left(\dot{\mathbf{X}}_{e k}-\dot{\mathbf{X}}_{H k}\right)+\mathbf{K}_{b}\left(\mathbf{X}_{e k}-\mathbf{X}_{H k}\right)=0
$$

where $\mathbf{M}_{e k}$ is the mass matrix of the beam element nodes connected to the $k$ th $(k=1,2,3,4)$ bearing; $\mathbf{X}_{e k}, \dot{\mathbf{X}}_{e k}$, and $\ddot{\mathbf{X}}_{e k}$ are the displacement, velocity, and acceleration vectors of the beam element nodes connected to the $k$ th $(k=1,2,3,4)$ bearing, respectively; $\mathbf{X}_{H k}$ and $\dot{\mathbf{X}}_{H k}$ denote the displacement and velocity vectors of the equivalent nodes of the gearbox unit connected to the $k$ th $(k=1,2,3,4)$ bearing, respectively.

3.3. Gearbox System. In order to establish the dynamic model of the gearbox, the dynamic parameters of the gearbox need to be obtained, including the mass matrix, the stiffness matrix, and the damping matrix. The gearbox nodes are divided into internal nodes and external nodes when the substructure method is employed to extract the gearbox's matrix information. The external nodes are acquired by coupling the nodes on the bearing hole's surface to the hole centre, and the remaining finite element nodes are the internal nodes. The gearbox mass, stiffness, and damping matrix can be extracted by a substructure method that condenses the internal nodes into external nodes. After that, the mass, the stiffness, and the damping matrix of the converted main node of the gearbox are assembled with the mass, stiffness, and damping matrix of the spiral bevel gear transmission system. The substructure method can avoid a large-scale finite element matrix, and it can be combined 


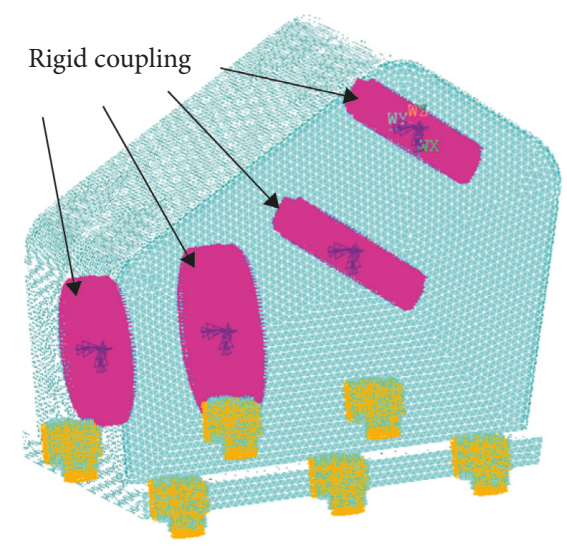

(a)

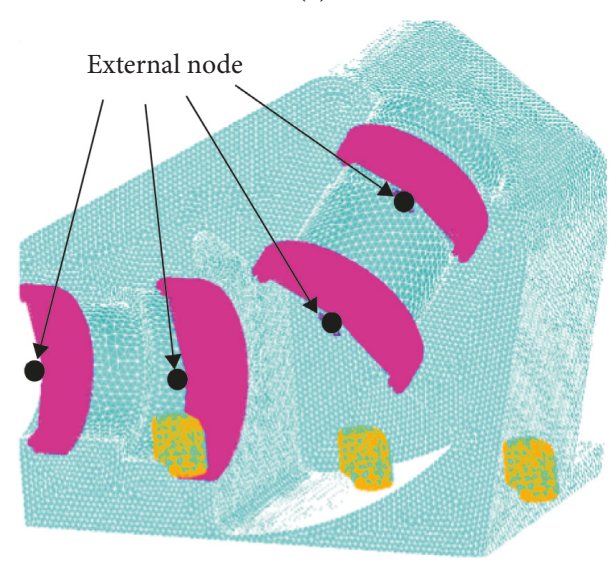

(b)

Figure 8: Finite element model diagram of the gearbox using the substructure method.

with the dynamic model of the transmission system conveniently.

Figure 8 shows a finite element model diagram of the gearbox using the substructure method. The gearbox is made of an aluminium alloy with a density of $2700 \mathrm{~kg} / \mathrm{m}^{3}$, an elastic modulus of $7.1 \times 10^{10} \mathrm{~Pa}$, and Poisson's ratio of 0.33 . The model includes 828873 nodes and 585756 elements. Taking the degrees-of-freedom of the translation in each direction and rotation around $X$ and $Y$ axes of the bearing hole centre nodes into account, meanwhile, the screw holes are imposed a fixed constraint at the bottom of the gearbox. Therefore, a $20 \times 20$ mass matrix $\mathbf{M}_{H}$ and a $20 \times 20$ stiffness matrix $\mathrm{K}_{H}$ are formed; Rayleigh damping is employed, i.e., $\mathbf{C}_{H}=\alpha_{H} \mathbf{M}_{H}+\beta_{H} \mathbf{K}_{H}$, where $\alpha_{H}$ and $\beta_{H}$ are the mass coefficient and the stiffness coefficient, respectively.

After polycondensation, the degrees-of-freedom of the gearbox is significantly reduced, and the dynamic equation can be expressed as follows:

$$
\mathbf{M}_{H} \ddot{\mathbf{x}}_{H}+\mathbf{C}_{H}\left(\dot{\mathbf{x}}_{H k}-\dot{\mathbf{x}}_{e k}\right)+\mathbf{K}_{H}\left(\mathbf{x}_{H k}-\mathbf{x}_{e k}\right)=0,
$$

where $\mathbf{M}_{H}=\left[\begin{array}{cccc}M_{H 11} & M_{H 12} & \cdots & M_{H 1 n} \\ M_{H 21} & M_{H 22} & \cdots & M_{H 2 n} \\ \vdots & \vdots & \ddots & \vdots \\ M_{H n 1} & M_{H n 2} & \cdots & M_{H n n}\end{array}\right]$ is the equivalent mass matrix of the gearbox substructure, in which $n$ is the number of the bearings; $\mathbf{K}_{H}=\left[\begin{array}{cccc}K_{H 11} & K_{H 12} & \cdots & K_{H 1 n} \\ K_{H 21} & K_{H 22} & \cdots & K_{H 2 n} \\ \vdots & \vdots & \ddots & \vdots \\ K_{H n 1} & K_{H n 2} & \cdots & K_{H n n}\end{array}\right]$, which is the equivalent stiffness matrix of the gearbox substructure; $\mathbf{C}_{H}=a_{H} \mathbf{M}_{H}+b_{H} \mathbf{K}_{H}$, which is the equivalent damping matrix of the gearbox substructure; $\mathbf{X}_{H}, \dot{\mathbf{X}}_{H}$, and $\ddot{\mathbf{X}}_{H}$ are the displacement, velocity, and acceleration vectors of the gearbox's main node, respectively.

3.4. Global Dynamics Equation of the System. After obtaining the dynamic equations of each unit, the dynamic equations of the whole system can be established. Combined with the differential equation of the gear shaft unit (7), the differential equation of the meshing element (15), the differential equation of the bearing element (20), and the motion equation of the gearbox element (21), the full coupling differential equations of the entire system can be written as follows:

$\mathbf{M x}(\mathbf{t})+(\mathbf{C}+\mathbf{\Omega G})[\dot{\mathbf{x}}(\mathbf{t})-\dot{\mathbf{e}}(\mathbf{t})]+\mathbf{K}(\mathbf{t})[\mathbf{x}(\mathbf{t})-\mathbf{e}(\mathbf{t})]=\mathbf{Q}(\mathbf{t})$,

where $\mathbf{M}, \mathbf{C}, \mathbf{G}$, and $\mathbf{K}$ are the generalized mass, damping, gyroscopic, and stiffness matrices, respectively. $\mathbf{X}, \dot{\mathbf{X}}$, and $\ddot{\mathbf{X}}$ are the generalized displacement, velocity, and acceleration vectors, respectively. $\mathbf{Q}$ is the excitation force vector of the system.

\section{Solution and Analysis of the Dynamic Equation of the Full Coupling System of the Spiral Bevel Gear}

From the derivation process and results, it can be determined that the full coupling system is a complex coupling dynamics question, and it is complicated to obtain satisfactory results using the theoretical analysis method. Meanwhile, the stiffness matrix of the entire dynamic equation of the system is a singular matrix, i.e., the system has rigid body displacement. In this article, the rigid body displacement is eliminated by imposing a fixed constraint on the torsional direction of the output end. Although the absolute displacement of each degrees-of-freedom will deviate from the actual one, the relative microvibration displacement has little effect. Then, the Newmark method is employed to calculate the numerical solution of the full coupling system. In order to obtain an accurate dynamic response, the step size is $1 / 200$ of the gear meshing frequency. The structural parameters of the rotating shaft of the full coupling system are shown in Table 2. The relevant parameters of the spiral bevel gear are revealed in Table 1, in which the time-varying meshing stiffness of the gear pair is obtained from Part 3.1; the stiffness and damping of the ball bearings are shown in Table 3, and the structural parameters of the gearbox are acquired from Section 3.3.

\subsection{Effect of the Gearbox Flexibility on the Dynamic Characteristics of the Spiral Bevel Gear Transmission System}

4.1.1. Influence of the Gearbox Flexibility on the Meshing Force. In order to investigate the gearbox flexibility's effect 
TABLE 2: Shaft element parameters.

\begin{tabular}{|c|c|c|c|c|c|c|c|c|}
\hline \multirow{3}{*}{$\begin{array}{l}\text { Node to node } \\
\text { Outer diameter } \\
\text { (mm) }\end{array}$} & \multicolumn{8}{|c|}{ Driving and driven shaft } \\
\hline & $1-2$ & $2-3$ & $3-4$ & $4-9$ & $10-15$ & $15-16$ & $16-17$ & $17-18$ \\
\hline & 48 & 57 & 60 & 75 & 75 & 60 & 57 & 48 \\
\hline $\begin{array}{l}\text { Inner diameter } \\
(\mathrm{mm})\end{array}$ & 44 & 45 & 45 & 52 & 52 & 45 & 45 & 44 \\
\hline $\begin{array}{l}\text { Shaft length } \\
(\mathrm{mm})\end{array}$ & 20 & 26 & 28 & 108 & 140 & 28 & 26 & 20 \\
\hline
\end{tabular}

TABLE 3: Bearing parameters.

\begin{tabular}{lcc}
\hline Stiffness & Bearing 1-2 & Bearing 3-4 \\
\hline$k_{x x}, k_{y y}(\mathrm{~N} / \mathrm{m})$ & $2 \times 10^{8}$ & $2 \times 10^{8}$ \\
$k_{z z}(\mathrm{~N} / \mathrm{m})$ & $1 \times 10^{8}$ & $1 \times 10^{8}$ \\
$k_{\theta x \theta x}, k_{\theta y \theta y}(\mathrm{Nm} / \mathrm{rad})$ & $1 \times 10^{6}$ & $1 \times 10^{6}$ \\
Damping & Bearing $1-2$ & Bearing 3-4 \\
$c(\mathrm{Ns} / \mathrm{m})$ & $1 \times 10^{3}$ & $1 \times 10^{3}$ \\
\hline
\end{tabular}

on the meshing force of the gear transmission system, the meshing force of the uncoupling model (only considering the spiral bevel gear transmission system) and the coupling model (the spiral bevel gear-gearbox coupling model considering the gearbox flexibility) are obtained. Figure 9 shows the amplitude-frequency response curve of the meshing force of the uncoupling and coupling mode at a rotation speed range of $200 \sim 8000 \mathrm{r} / \mathrm{min}$. As seen in Figure 9, the stiffness of the gearbox is introduced into the spiral bevel gear transmission system, which reduces the overall stiffness of the system, and absorbs and transmits part of the energy, resulting in a reduction in the meshing force at all rotational speeds. However, the magnitude of reduction in the meshing force is different at various rotational speeds. By comparing Figure 9(a) with Figure 9(b), it can be observed that, with the variety of the torque, the effect of the gearbox flexibility on meshing force is also varied. Under torques of $300 \mathrm{Nm}$ and $600 \mathrm{Nm}$, the meshing forces of the uncoupling model and the coupling model are calculated, respectively, at rotating speeds of $3000 \mathrm{r} / \mathrm{min}, 4700 \mathrm{r} / \mathrm{min}$, and $7100 \mathrm{r} / \mathrm{min}$. The specific values are shown in Table 4 . By analysing the data in Table 4, it is demonstrated that the effect of the gearbox flexibility on the meshing force is also larger when the torque is larger at the same speed.

\subsubsection{Influence of the Gearbox Flexibility on the Bearing} Force. Similarly, to study the influence of the gearbox flexibility on the bearing force, the differential equations of the system are solved in order to obtain the amplitudefrequency response curves of the bearing force of the uncoupling model and coupling model in the speed range of $200 \sim 8000 \mathrm{r} / \mathrm{min}$, as shown in Figure 10(a). It can be observed that with the variety of the rotating speed, the bearing force decreases in the entire rotating speed range while taking the gearbox stiffness into account, and the most significant decrease of the bearing force occurs at the resonance point. The main reason for this is that the vibration of the gearbox is introduced into the entire dynamic system, and the variety of the system stiffness affects the supporting force significantly, and this also means that the force transmitted by the transmission system to the other structural systems is reduced considerably. The gearbox flexibility in the transmission system helps obtain more accurate dynamic analysis results, which provides a theoretical basis for the optimization design and vibration and noise reduction of the system. Then, the amplitude-frequency response curve of the bearing force of the uncoupling and coupling gearbox in the rotating speed range of 200 $8000 \mathrm{r} / \mathrm{min}$ is obtained when the torque increases, which is revealed in Figure 10(b). To facilitate the analysis, under torques of $300 \mathrm{Nm}$ and $600 \mathrm{Nm}$, the bearing forces of uncoupling and coupling the gearbox at rotating speeds of $3000 \mathrm{r} / \mathrm{min}, 4700 \mathrm{r} / \mathrm{min}$, and $7100 \mathrm{r} / \mathrm{min}$ are calculated, respectively, as shown in Table 5. By observing the data in the table, it can be determined that the change rate of the bearing force is large when the torque is large at the same speed.

According to the above analysis, the flexibility of the gearbox has an impact on the meshing force and the bearing force, of which the influence on the bearing force is prominent. In the analysis of the overall dynamic response of the coupling system supported by the thin-walled gearbox, the effect of the gearbox flexibility needs to be taken into account.

4.2. Influence of the Shaft Angle on the Dynamic Characteristics of the Spiral Bevel Gear Full Coupling System. Based on the research in the previous section, the influence of the flexibility of the thin-walled gearbox on the spiral bevel gear transmission system cannot be ignored. Thus, this section directly studies the effect of the shaft angle on the dynamic characteristics of the spiral bevel gear-shaft-bearing-gearbox full coupling system.

\subsubsection{Effect of the Shaft Angle on the Axis Trajectory of the} Gear. Studying the axis locus of the critical nodes can predict whether the geared rotor transmission system will encounter rub-impact during operation or not, and the investigation of the gear's axis locus is especially helpful in understanding the meshing status of the gear. It is assumed that the speed of the driving spiral bevel gear is $4200 \mathrm{r} / \mathrm{min}$, the torque is $600 \mathrm{Nm}$, and the other parameters keep invariant. The variation of the axial trajectory of the driven spiral bevel gear is analysed when the shaft angles of the spiral bevel gear transmission system are $70,90,110$, and 126, as shown in Figure 11. The centre of the trajectory of the driven spiral bevel gear is varied when the shaft angle has diverse values, as shown in Figure 11(a). The centres of the axis locus under each shaft angle are set to the same position to observe the variety of the direction and size of the axis locus. It can be seen in Figure 11(b) that the variation in the shaft angle not only affects the direction of the axis locus but also alters the amplitude of the axis locus. The calculation shows that the axis locus of the other nodes will also change with the variety of the shaft angle. Therefore, the impact of the shaft angle must be taken into account when studying the 


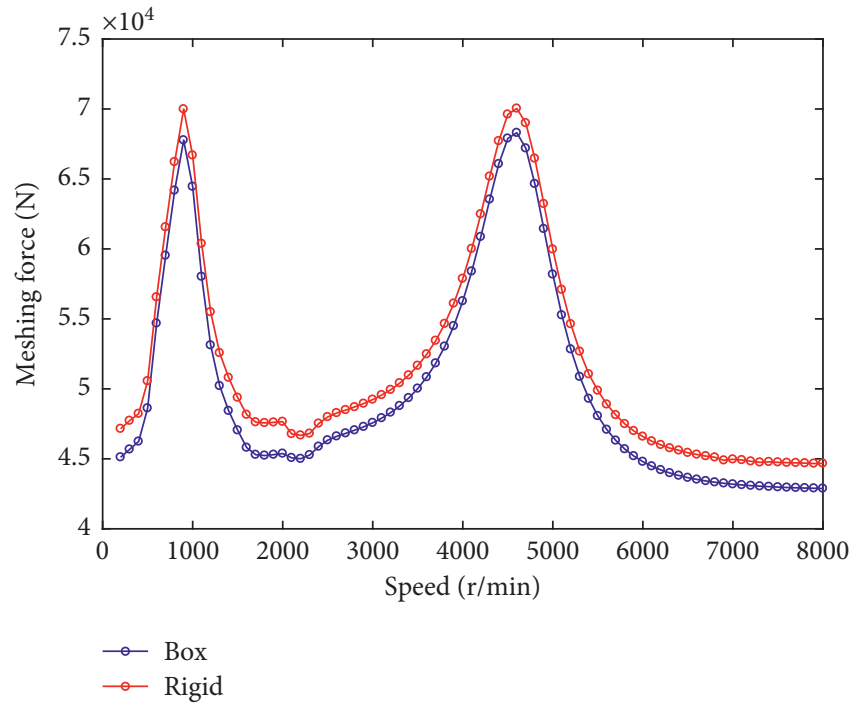

(a)

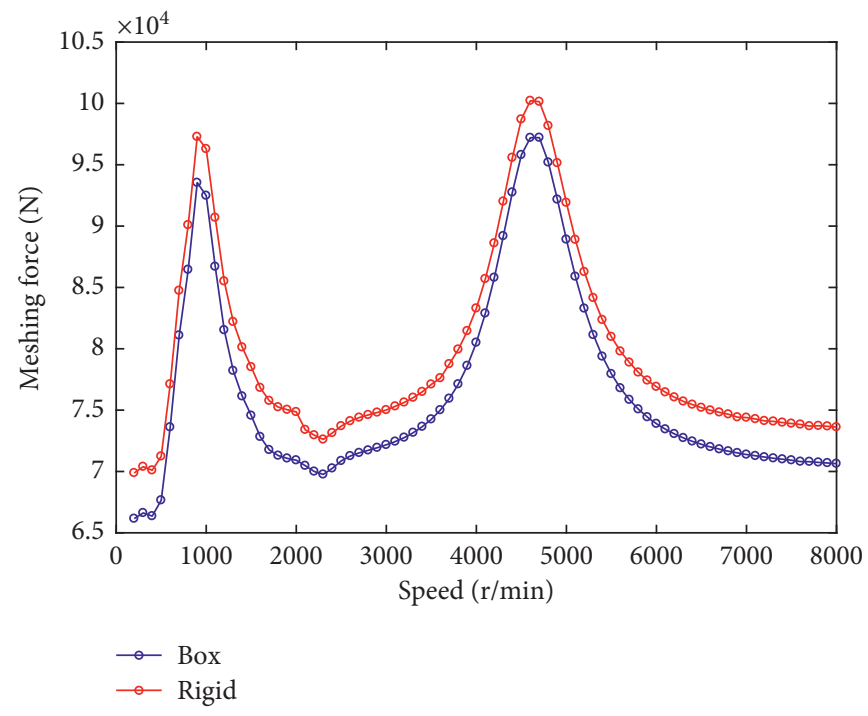

(b)

FIgURE 9: Amplitude-frequency response curve of the meshing forces of the uncoupling and coupling model under different torques. (a) $T=300 \mathrm{Nm}$. (b) $T=600 \mathrm{Nm}$.

TABLE 4: Change rate of the meshing force under different models.

\begin{tabular}{lcccc}
\hline Torque $(\mathrm{Nm})$ & Speed $(\mathrm{r} / \mathrm{min})$ & Meshing force of coupling model $(\mathrm{N})$ & Meshing force of uncoupled model (N) & Rate of change $(\%)$ \\
\hline \multirow{3}{*}{300} & 3000 & 46570 & 49240 & 5.4 \\
& 4700 & 66190 & 69000 & 4.1 \\
\hline \multirow{2}{*}{600} & 7100 & 42130 & 74920 & 6.2 \\
& 3000 & 71170 & 10010 & 6.4 \\
& 4700 & 95210 & 75880 & 7.8 \\
\hline
\end{tabular}

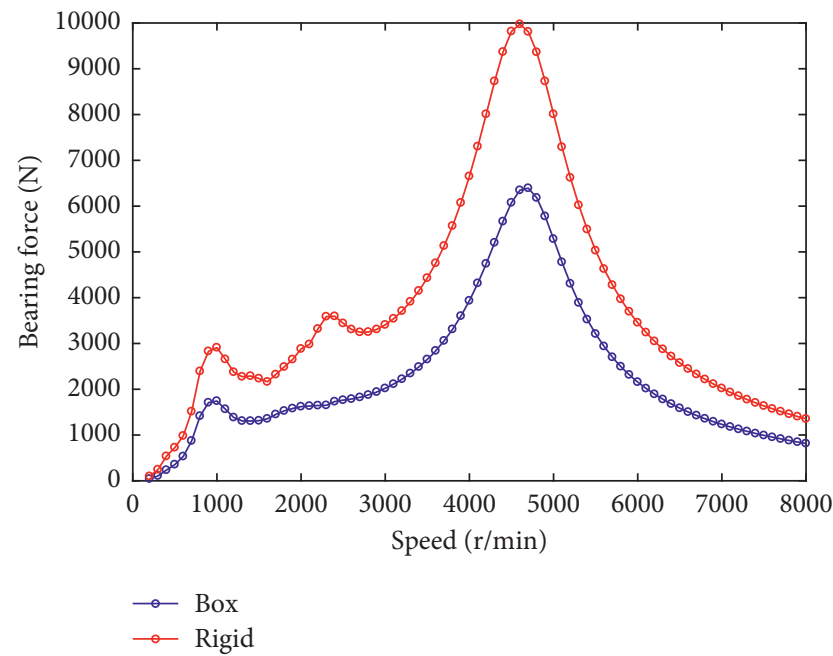

(a)

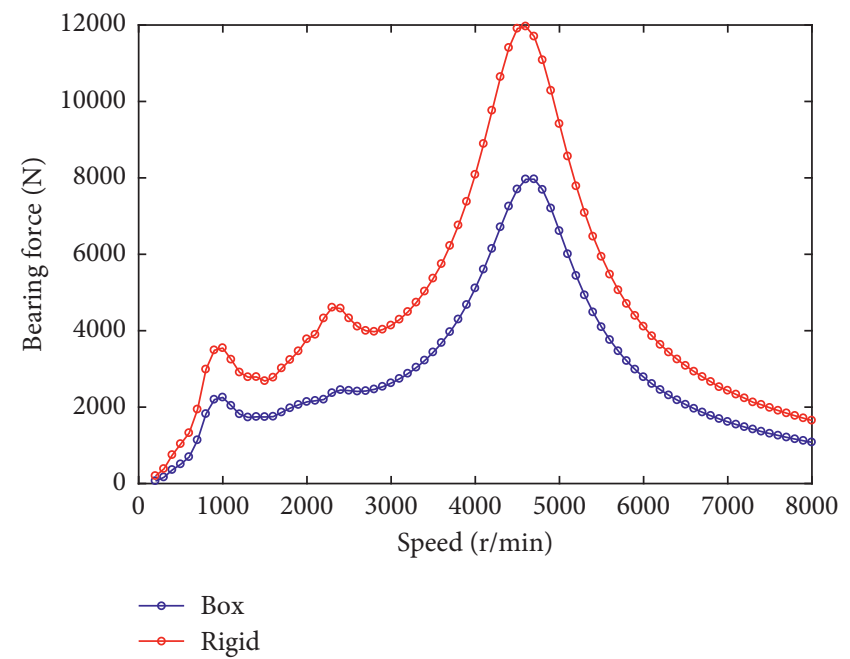

(b)

FIgURE 10: Amplitude-frequency response curves of the bearing forces of the uncoupling and coupling model under different torques. (a) $T=300 \mathrm{Nm}$. (b) $T=600 \mathrm{Nm}$.

vibration features of the nonorthogonal spiral bevel gearshaft-bearing-gearbox full coupling system.

4.2.2. Effect of the Shaft Angle on the Meshing Force and Bearing Force. Supposing that the driving gear's rotation speed is $4200 \mathrm{r} / \mathrm{min}$, the torque is $600 \mathrm{Nm}$, and other parameters kept invariant, then the meshing force and the bearing force variation in each direction are obtained when the shaft angle is $70,90,110$, and 126 , respectively, as shown in Figure 12. It can be demonstrated from the 
TABLE 5: Change rate of the bearing force under different models.

\begin{tabular}{lcccc}
\hline Torque $(\mathrm{Nm})$ & Speed $(\mathrm{r} / \mathrm{min})$ & Bearing force of coupling model $(\mathrm{N})$ & Bearing force of uncoupling model $(\mathrm{N})$ & Rate of change $(\%)$ \\
\hline \multirow{3}{*}{300} & 3000 & 2213 & 3307 & 33 \\
& 4700 & 6393 & 9808 & 35 \\
\hline \multirow{3}{*}{600} & 7100 & 1278 & 4292 & 32 \\
& 3000 & 2741 & 11700 & 37 \\
& 4700 & 7964 & 2431 & 30 \\
\hline
\end{tabular}

figure that the meshing force and the bearing force of the spiral bevel gear pair are various with the variety of the shaft angles. The meshing force varies because the pitch angles of the pinion and the gear are various under different shaft angles, and the projection results of the vibration displacement of the gear pair in various directions to the meshing line vary. At the same time, the force's components decomposed into diverse directions are also different, resulting in variations in the bearing force for each direction. In conclusion, the vibration behaviours of the spiral bevel gear pair and the full coupling system will vary with the variety of the shaft angle.

\subsection{Influence of Unbalance on the Dynamic Characteristics of a Spiral Bevel Gear Full Coupling System}

4.3.1. The Influence of the Unbalance on Frequency Response Characteristics of the Coupling System. An unbalance amount, which is equal to $5 \times 10^{-4} \mathrm{~kg} \cdot \mathrm{m}$, is applied to the drive shaft's node 4 , with no imbalance given to the other nodes. The driving shaft speed $n_{1}$ is in the range of 200 800 r/min, and the three-dimensional spectrum of the full coupling system at the driving and driven gears are obtained, respectively, as shown in Figure 13. As seen from Figure 13(a), because of the coupling effect between the rotor and the gear, the $X$-direction displacement vibration spectrum of the driving gear includes the rotation frequency of the driving shaft $f_{1}$, the gear meshing frequency $f_{\mathrm{m}}$, and its harmonic frequency $2 f_{\mathrm{m}}$. Meanwhile, it can be seen from Figure 13(b) that the torsional vibration spectrum of the driving gear also includes the rotation frequency of the driving shaft $f_{1}$, the meshing frequency $f_{\mathrm{m}}$, and its harmonic frequency $2 f_{\mathrm{m}}$. As seen from Figure $13(\mathrm{c})$, the $X$-direction displacement vibration spectrum of the driven gear includes the meshing frequency $f_{\mathrm{m}}$ and its harmonic frequency $2 f_{\mathrm{m}}$. The imbalance of the driving shaft has little effect on the vibration displacement of the driven gear in the $X$ direction, where the rotation frequency amplitude of the driving shaft is small, which is not revealed in the figure. As seen from Figure 13(d), because of the coupling effect of bending and torsion of the spiral bevel gear pair, the driven gear's torsional vibration not only contains the meshing frequency $f_{\mathrm{m}}$ and its harmonic frequency $2 f_{\mathrm{m}}$ but also the driving shaft's rotation frequency $f_{1}$, where the rotational frequency amplitude increases with the rise of the speed. Thus, the effect of the imbalance of the rotating shaft on the gear's vibration in the torsional direction is more prominent than that on the lateral vibration.

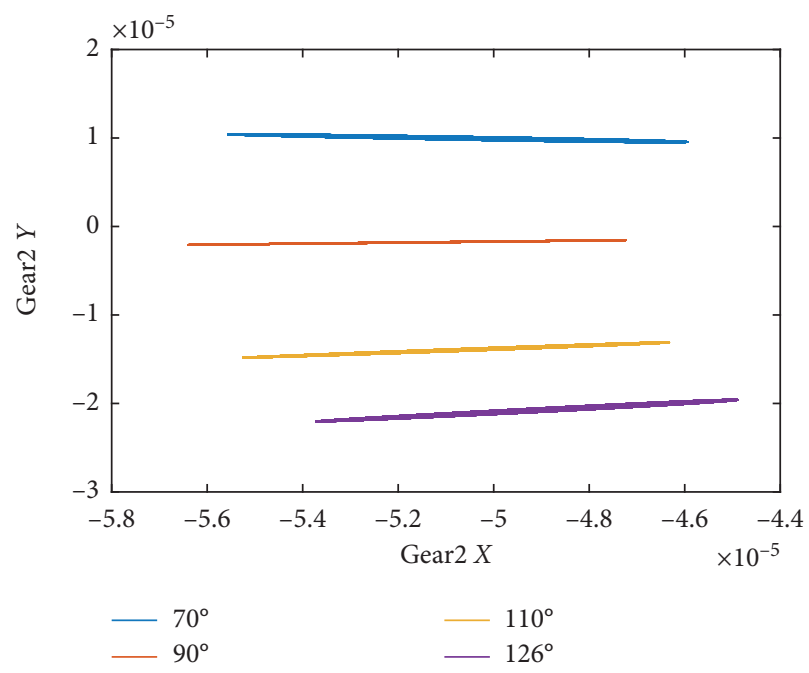

(a)

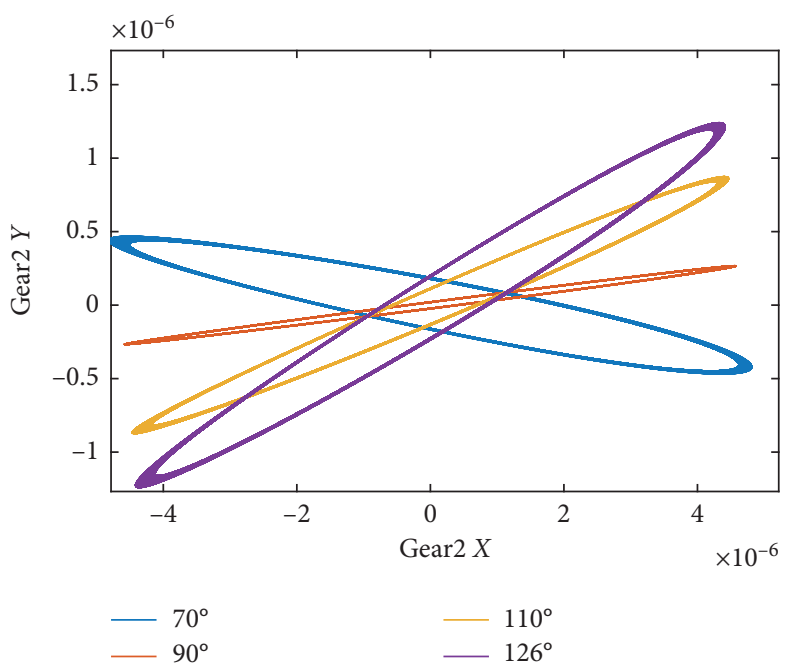

(b)

FIgURE 11: Axis trajectory diagram of a driven gear under various shaft angles.

The unbalance amount applied on the driving shaft's node 4 is changed to $10 \times 10^{-4} \mathrm{~kg} \cdot \mathrm{m}$, and the other conditions remain unchanged. The speed of the driving shaft $n_{1}$ varies from $200 \mathrm{r} / \mathrm{min}$ to $8000 \mathrm{r} / \mathrm{min}$, and the three-dimensional spectrum of the full coupling system at the pinion and gear are acquired, as shown in Figure 14. Comparing Figures 13(a) and 13(b) and 14(a) and 14(b), it can be 


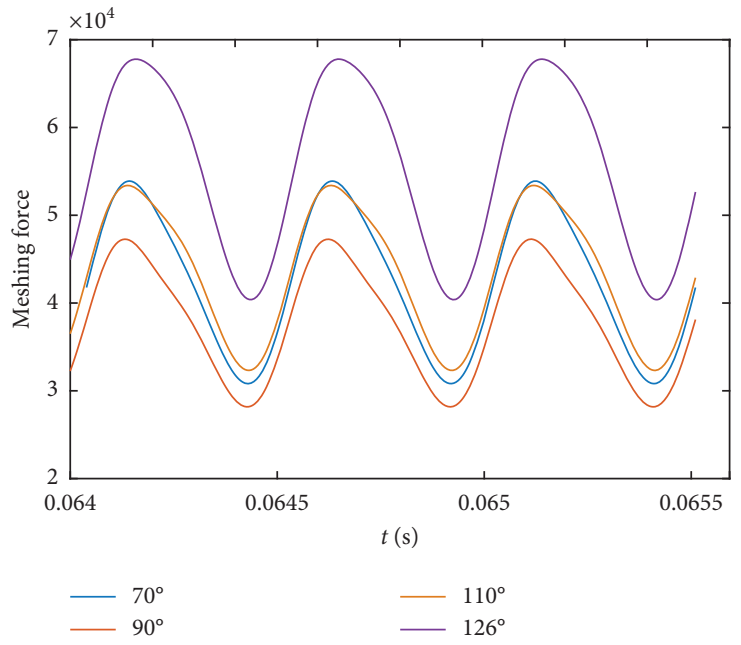

(a)

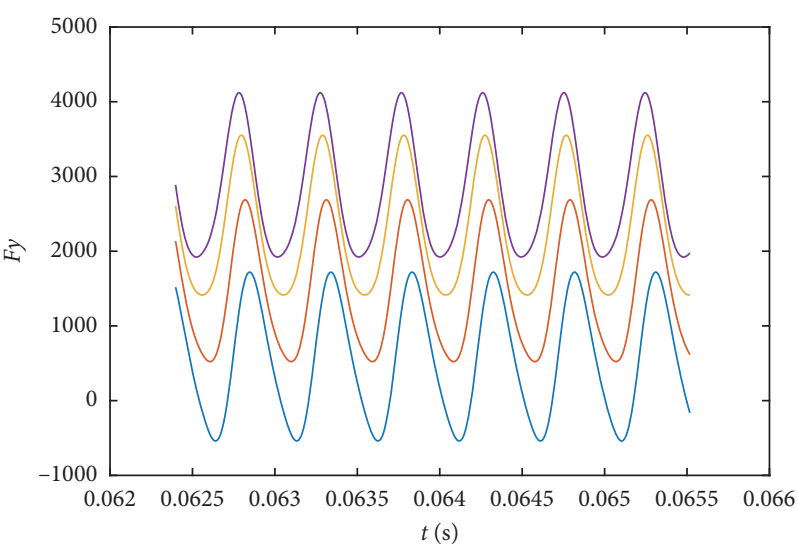

$\begin{array}{ll}70^{\circ} \\ -90^{\circ} & 110^{\circ} \\ -126^{\circ}\end{array}$

(c)

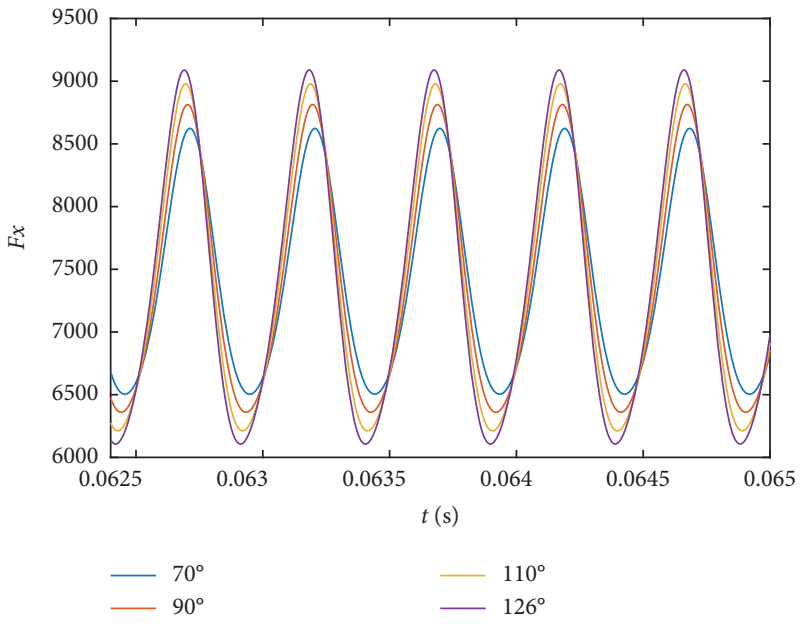

(b)

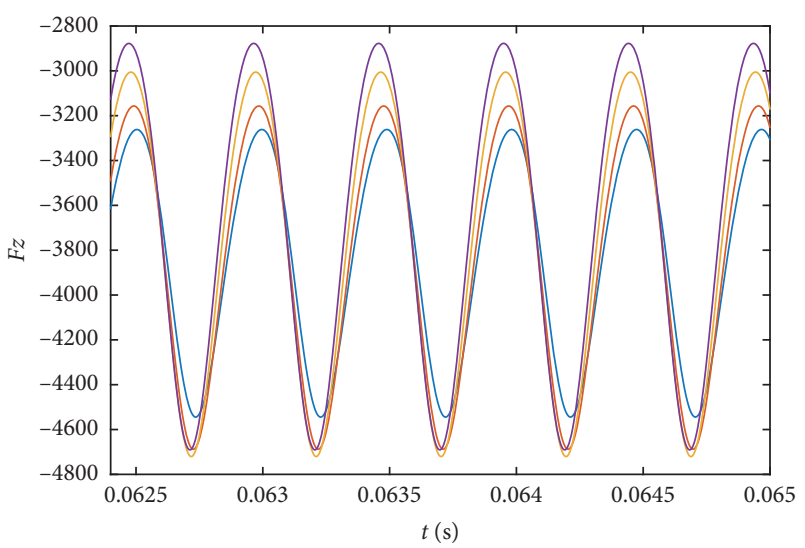

$-70^{\circ}$

$110^{\circ}$

(d)

Figure 12: Meshing force and bearing force under various shaft angles. (a) Meshing force. (b) Bearing force in the $X$ direction. (c) Bearing force in the $Y$ direction. (d) Bearing force in the $Z$ direction.

demonstrated that the amplitude corresponding to the rotating frequency of the driving gear in the lateral and torsional vibration spectrograms increases significantly when the imbalance on the driving shaft is rising, while the amplitude corresponding to the meshing frequency hardly changes. It can be seen from Figure 14(c) that the driven gear's vibration spectrum exhibits the driving shaft's rotating frequency $f_{1}$ at a high rotational speed, indicating that the coupling effect of the driving shaft's imbalance on the driven gear's vibration displacement is also risen with an increase in the unbalance of the driving shaft. Comparing Figures 13(d) and $14(\mathrm{~d})$, it can be revealed that the amplitude of the rotation frequency $f_{1}$ rises in the driven gear's torsional vibration spectrum, which also indicates that the increase of the driving shaft's unbalance increases the effect of the driven gear's torsional vibration, and the increased amplitude is more obvious than that of the transverse vibration.
4.3.2. Influence of the Unbalance on the Meshing Force and Bearing Force. In order to analyse the influence of the unbalance of the rotating shaft on the meshing force and the bearing force, the unbalance amount on the driving shaft's node 4 is taken as $0,5 \times 10^{-4} \mathrm{~kg} \cdot \mathrm{m}$, and $10 \times 10^{-4} \mathrm{~kg} \cdot \mathrm{m}$, respectively. The amplitude-frequency response curves of the meshing force and the bearing force within a rotation speed range of 200 8000 r/min are calculated, as shown in Figure 15. It can be revealed from the figure that the meshing force and the bearing force have little influence at low rotational speeds with the increase of the eccentricity; however, the eccentricity has a great influence on the meshing force and bearing force when speed continuously increase. Therefore, when the speed of the full coupling system is high, the eccentric amount of the rotating shaft should be reduced to diminish its impact on the meshing force and bearing force so as to ensure the stable and reliable operation of the system. 


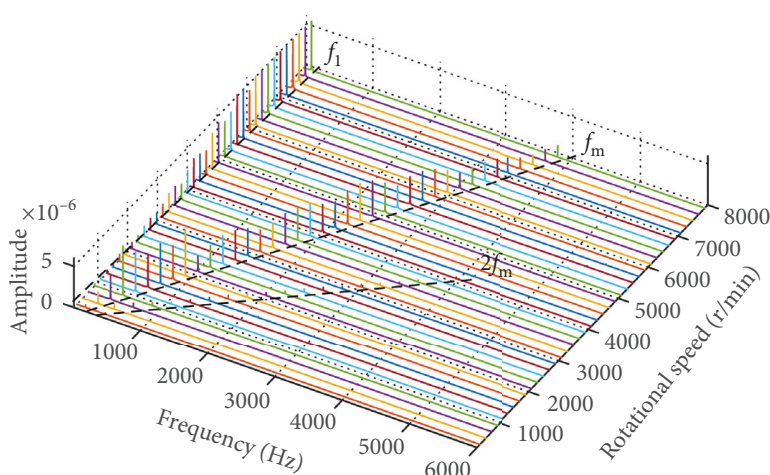

(a)

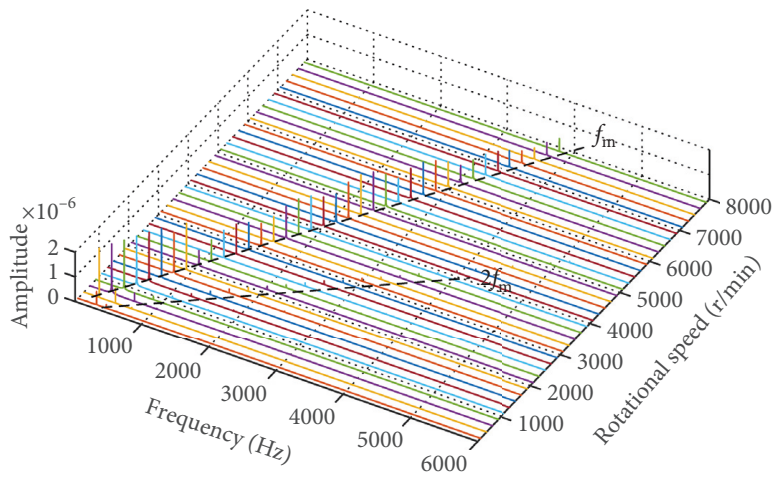

(c)

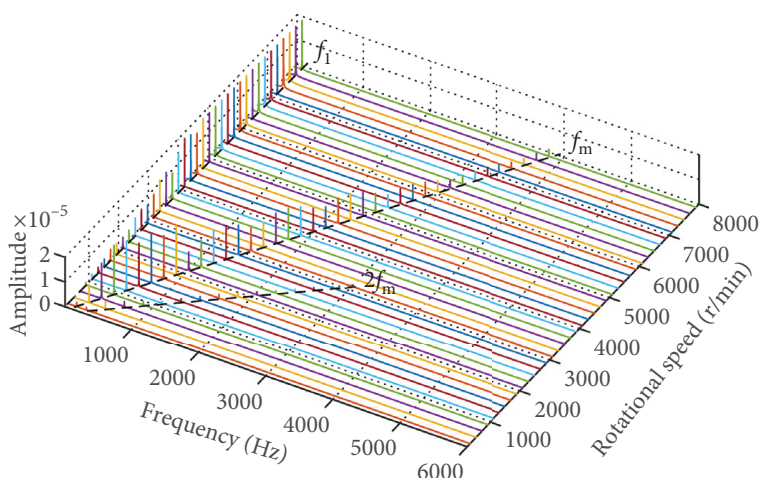

(b)

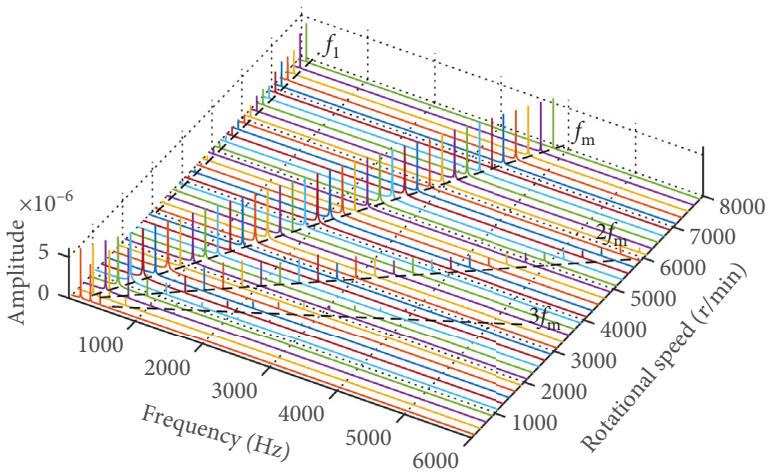

(d)

Figure 13: Three-dimensional spectrum of the coupling system as the unbalance is $5 \times 10^{-4} \mathrm{~kg} \cdot \mathrm{m}$. (a) Lateral vibration of the driving gear in the $X$ direction. (b) Torsional vibration of the driving gear. (c) Lateral vibration of the driven gear in the $X$ direction. (d) Torsional vibration of the driven gear.

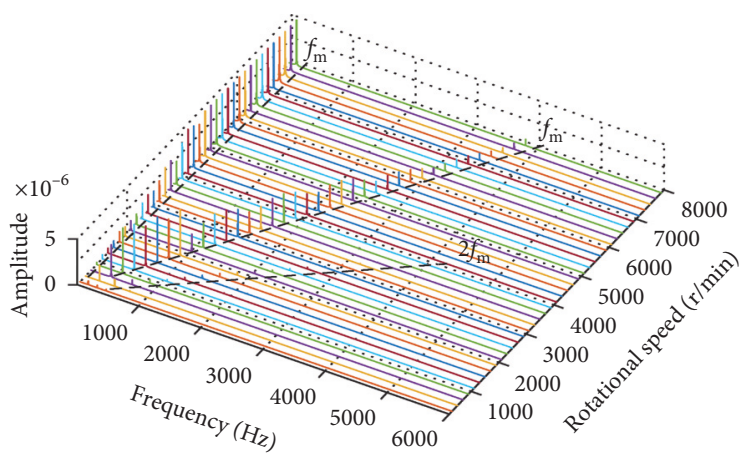

(a)

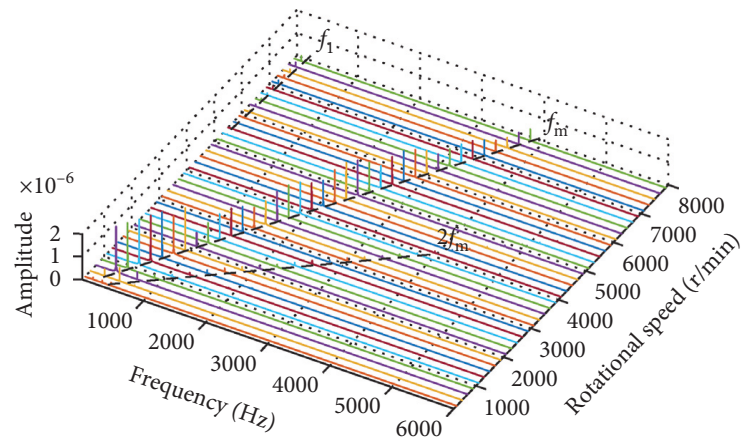

(c)

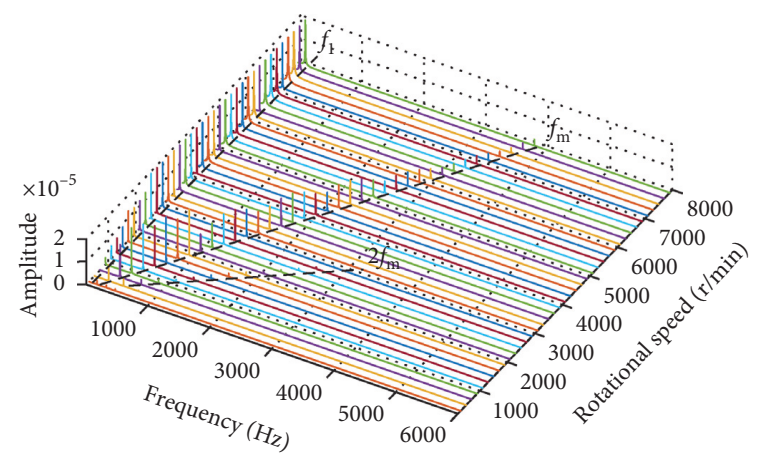

(b)

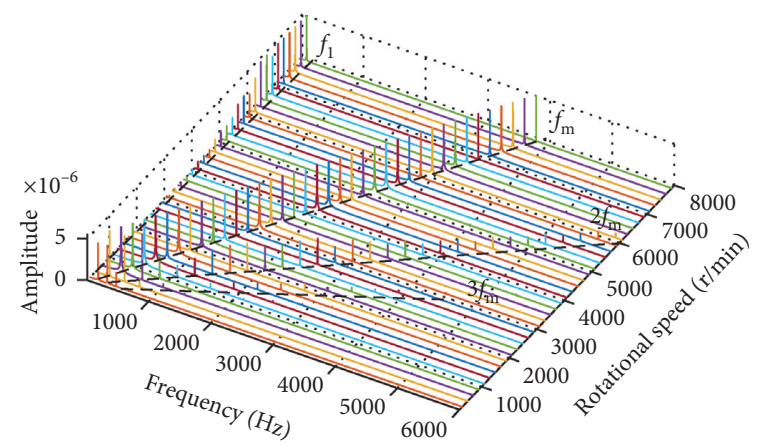

(d)

FiguRE 14: Three-dimensional spectrum of the coupling system as the unbalance is $10 \times 10^{-4} \mathrm{~kg} \cdot \mathrm{m}$. (a) Lateral vibration of the driving gear in the $X$ direction. (b) Torsional vibration of the driving gear. (c) Lateral vibration of the driven gear in the $X$ direction. (d) Torsional vibration of the driven gear. 


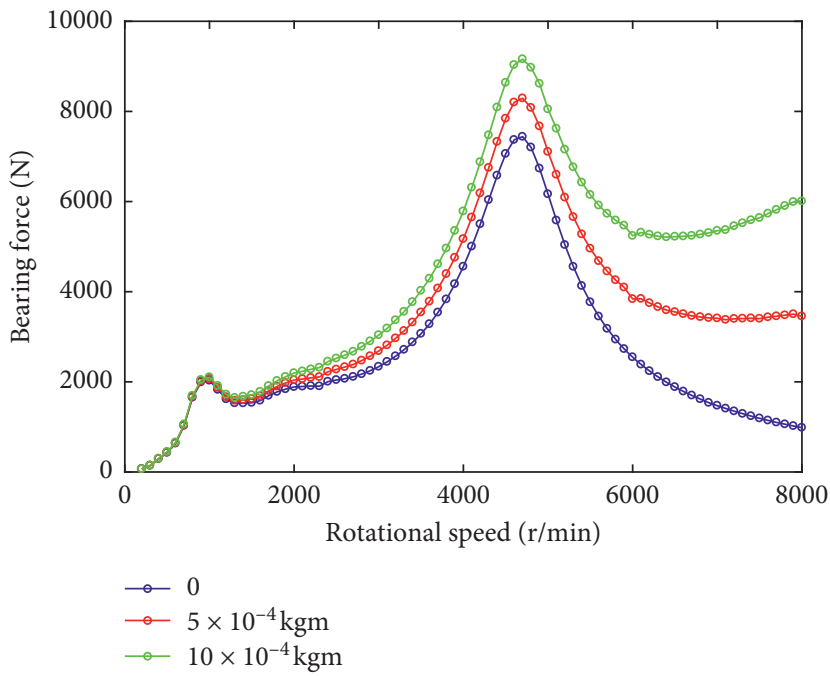

(a)

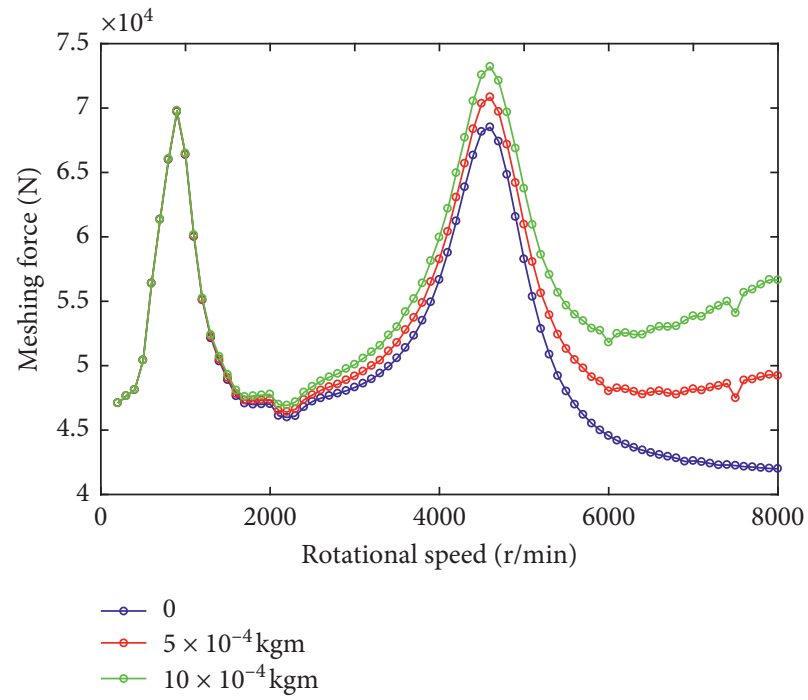

(b)

FIGURE 15: Amplitude-frequency response curves of the meshing force and the bearing force. (a) Amplitude-frequency response curve of the bearing force. (b) Amplitude-frequency response curve of the meshing force.

\section{Conclusion}

A full coupling dynamic model of the spiral bevel gear was built, taking the flexibility of the shaft, the bearing supporting, the unbalance amount, a time-varying meshing stiffness, a comprehensive transmission error, and the gearbox flexibility into account. The Timoshenko beam element was employed to simulate the flexible shaft in the model, and the gears and bearings were treated according to the concentrated mass. Because of the complex structure of the gearbox system, the substructure method was applied to extract its mass, stiffness, and damping matrix. The full coupling dynamic equations of the spiral bevel gear-shaftbearing-gearbox were constructed, and the coupling dynamic equations were solved via the Newmark numerical algorithm. The following conclusions were obtained.

The stiffness of the gearbox affects the meshing force and bearing force of the spiral bevel gear transmission system. The meshing force and bearing forces are smaller than those of the rigid support when considering the gearbox flexibility, wherein the gearbox flexibility has a more significant effect on the bearing force.

The shaft angle of the full coupling system of the nonorthogonal spiral bevel gear affects the axis locus, meshing force, and bearing force simultaneously. For various shaft angles, the position, size, and direction of the gear's axis locus vary. Because the pitch angles of the pinion and gear are different under various shaft angles, the meshing force and bearing force of the system also vary. As a result, the vibrational characteristics of the gear pair and the entire coupling system also change.

Because of the coupling of bending and torsion of the system, the unbalance of the rotating shaft exerts an effect on the vibration of the spiral bevel gear transmission system in all directions, where the torsional vibration has the greatest influence, and the effect increase with the variety of unbalance. The unbalance of the rotating shaft also affects the meshing force and the bearing force. The influence is little at a low rotational speed. However, the unbalance exerts a significant effect on the meshing force and bearing force when speed continuously increases.

\section{Data Availability}

All the data studied in this article are derived from a specific type of helicopter tail drive system, ensuring that the research content is close to the actual work situation.

\section{Conflicts of Interest}

The authors declare that they have no potential conflicts of interest.

\section{Acknowledgments}

This work was supported by the National Natural Science Foundation of China (nos. 51775265 and 51775277).

\section{References}

[1] S. Wang, Y. W. Shen, and H. J. Dong, "Nonlinear dynamical characteristics of a spiral bevel gear system with backlash and time-varying stiffness," Chinese Journal of Mechanical Engineering, vol. 39, no. 02, pp. 28-31, 2003, in Chinese.

[2] Z. H. Feng and C. S. Song, "Effects of geometry design parameters on the static strength and dynamics for spiral bevel gear," International Journal of Rotating Machinery, vol. 2017, Article ID 6842938, 8 pages, 2017.

[3] L. H. Wang, Y. Y. Huang, R. F. Li, and T. J. Lin, "Study on nonlinear vibration characteristics of spiral bevel transmission system," China Mechanical Engineering, vol. 18, no. 3, pp. 260-264, 2007, in Chinese.

[4] J.-Y. Tang, Z.-H. Hu, L.-J. Wu, and S.-Y. Chen, "Effect of static transmission error on dynamic responses of spiral bevel 
gears," Journal of Central South University, vol. 20, no. 3, pp. 640-647, 2013.

[5] Y. S. Fan, S. M. Wang, Z. Yang, and H. X. Liu, "Vibration analysis method for multi-rotor system geared by angular spiral bevel gears," Journal of Harbin Institute of Technology, vol. 43, no. 3, pp. 111-116, 2011, in Chinese.

[6] Y. Cheng and T. C. Lim, "Vibration analysis of hypoid transmissions applying an exact geometry-based gear mesh theory," Journal of Sound and Vibration, vol. 240, no. 3, pp. 519-543, 2001.

[7] J. Yang and T. C. Lim, "Influence of propeller shaft bending vibration on drivetrain gear dynamics," International Journal of Automotive Technology, vol. 16, no. 1, pp. 57-65, 2015.

[8] J. Wang, T. C. Lim, and M. Li, "Dynamics of a hypoid gear pair considering the effects of time-varying mesh parameters and backlash nonlinearity," Journal of Sound and Vibration, vol. 308, no. 1-2, pp. 302-329, 2007.

[9] J. L. Xu, L. Wan, and W. X. Luo, "Influence of bearing stiffness on the nonlinear dynamics of a shaft-final drive system," Shock and Vibration, vol. 2016, Article ID 3524609, 14 pages, 2016.

[10] J. L. Xu, F. C. Zeng, and X. G. Su, "Coupled bending-torsional nonlinear vibration and bifurcation characteristics of spiral bevel gear system," Shock and Vibration, vol. 2017, Article ID 6835301, 14 pages, 2017.

[11] D. Yassine, H. Ahmed, W. Lassaad, and H. Mohamed, "Effects of gear mesh fluctuation and defaults on the dynamic behavior of two-stage straight bevel system," Mechanism and Machine Theory, vol. 82, no. 24, pp. 71-86, 2014.

[12] T. Peng, Coupled Multi-Body Dynamic and Vibration Analysis of Hypoid and Bevel Geared Rotor System, University of Cincinnati, Cincinnati, OH, USA, 2010.

[13] Y. N. Li, G. Y. Li, and L. Zheng, "Influence of asymmetric mesh stiffness on dynamics of spiral bevel gear transmission system," Mathematical Problems in Engineering, vol. 2010, Article ID 124148, 13 pages, 2010.

[14] J.-S. Wu and I.-H. Yang, "Computer method for torsion-andflexure-coupled forced vibration of shafting system with damping," Journal of Sound and Vibration, vol. 180, no. 3, pp. 417-435, 1995.

[15] S.-T. Choi and S.-Y. Mau, "Dynamic analysis of geared rotorbearing systems by the transfer matrix method," Journal of Mechanical Design, vol. 123, no. 4, pp. 562-568, 2001.

[16] S. V. Neriya, R. B. Bhat, and T. S. Sankar, "The coupled torsional-flexural vibration of a geared shaft system using finite element method," The Shock and Vibration Bulletin, vol. 55, no. 3, pp. 13-251, 1985.

[17] A. Kahraman, H. Nevzat Ozguven, D. R. Houser, and J. J. Zakrajsek, Dynamic Analysis of Geared Rotors by Finite Elements, NASA, Washington, DC, USA, 2015.

[18] M. Kubur, A. Kahraman, D. M. Zini, and K. Kienzle, "Dynamic analysis of a multi-shaft helical gear transmission by finite elements: model and experiment," Journal of Vibration and Acoustics, vol. 126, no. 7, pp. 398-406, 2004.

[19] Y. Zhang, Q. Wang, H. Ma, J. Huang, and C. Zhao, "Dynamic analysis of three-dimensional helical geared rotor system with geometric eccentricity," Journal of Mechanical Science and Technology, vol. 27, no. 11, pp. 3231-3242, 2013.

[20] S. Chen, J. Tang, Y. Li, and Z. Hu, "Rotordynamics analysis of a double-helical gear transmission system," Meccanica, vol. 51, no. 1, pp. 251-268, 2016.

[21] M. Li and H. Y. Hu, "Dynamic analysis of a spiral bevel-geared rotor-bearing system," Journal of Sound and Vibration, vol. 259, no. 3, pp. 605-624, 2003.
[22] X. Hua, T. C. Lim, T. Peng, and W. E. Wali, "Dynamic analysis of spiral bevel geared rotor systems applying finite elements and enhanced lumped parameters," International Journal of Automotive Technology, vol. 13, no. 1, pp. 97-107, 2012.

[23] S. D. Yavuz, Z. B. Saribay, and E. Cigeroglu, "Nonlinear timevarying dynamic analysis of a spiral bevel geared system," Nonlinear Dynamics, vol. 92, no. 4, pp. 1901-1919, 2018.

[24] F. K. Choy, Y. K. Tu, J. J. Zakrajsek, and D. P. Townsend, "Effects of gear box vibration and mass imbalance on the dynamics of multi-stage gear transmissions," NASA, Washington, DC, USA, 1991.

[25] F. K. Choy, Y. K. Ruan, R. K. Tu, J. J. Zakrajsek, and D. P. Townsend, "Modal analysis of multistage gear systems coupled with gearbox vibrations," NASA, Washington, DC, USA, 1991.

[26] Y. Ren, S. Chang, G. Liu, L. Wu, and T. C. Lim, "Impedance synthesis based vibration analysis of geared transmission system," Shock and Vibration, vol. 2017, Article ID 4846532, 14 pages, 2017.

[27] J. Wei, A. Zhang, D. Qin et al., "A coupling dynamics analysis method for a multistage planetary gear system," Mechanism and Machine Theory, vol. 110, pp. 27-49, 2017.

[28] F. Concli, L. Cortese, R. Vidoni, F. Nalli, and G. Carabin, “A mixed FEM and lumped-parameter dynamic model for evaluating the modal properties of planetary gearboxes," Journal of Mechanical Science and Technology, vol. 32, no. 7, pp. 3047-3056, 2018.

[29] J. R. Hutchinson, "Shear coefficients for Timoshenko beam theory," Journal of Applied Mechanics, vol. 68, no. 1, pp. 87-92, 2001.

[30] M. I. Friswell, J. E. T. Penny, S. D. Garvey, and A. W. Lees, Dynamics of Rotating Machines, Cambridge University Press, London, UK, 2010. 


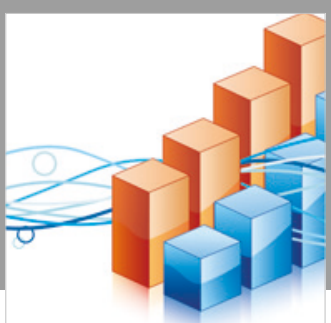

Advances in

Operations Research

\section{-n-m}
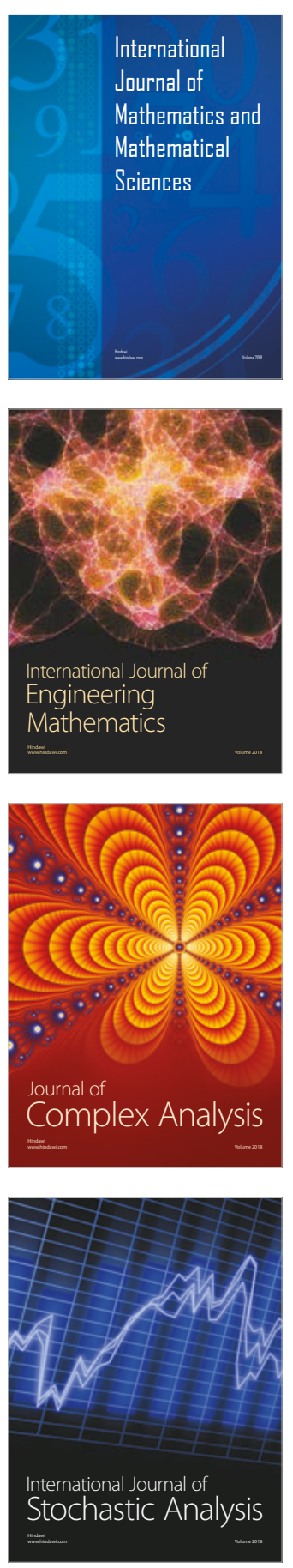
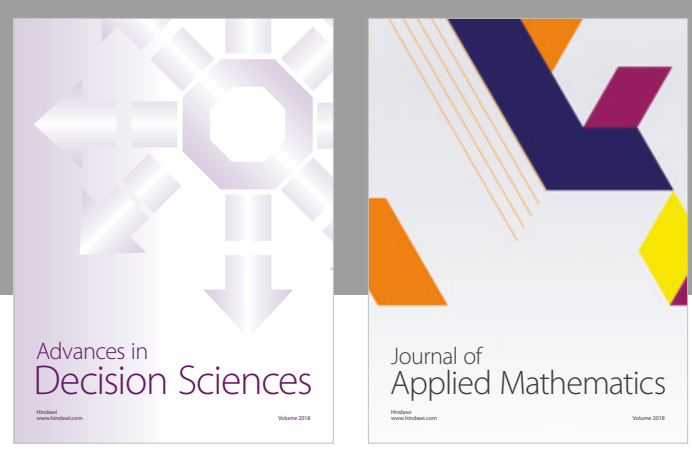

Journal of

Applied Mathematics
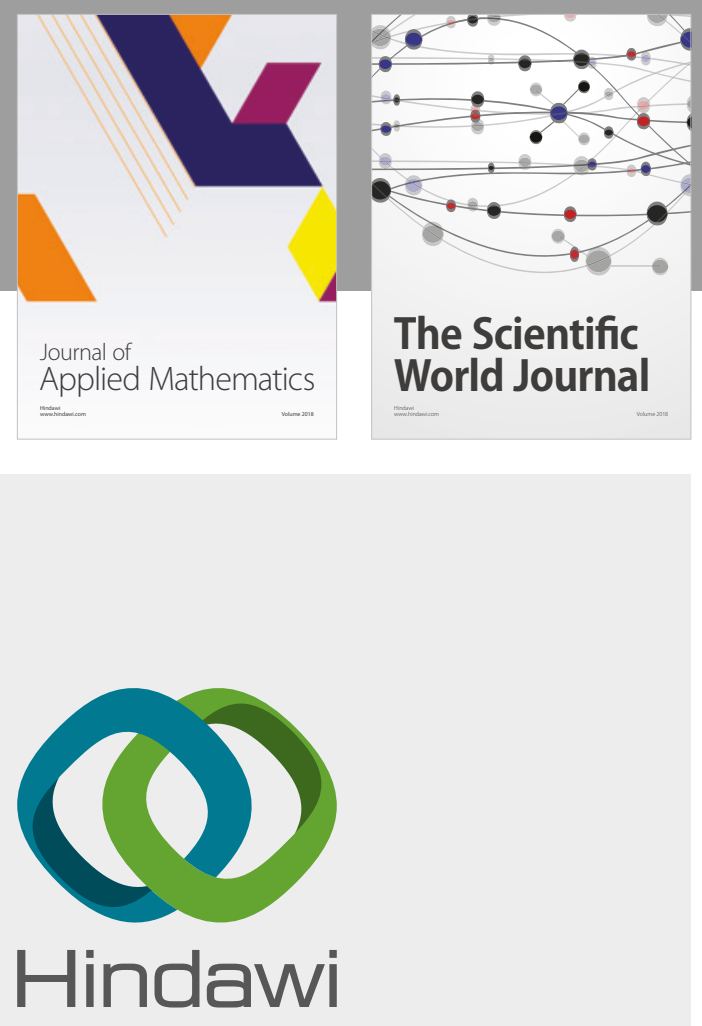

Submit your manuscripts at

www.hindawi.com

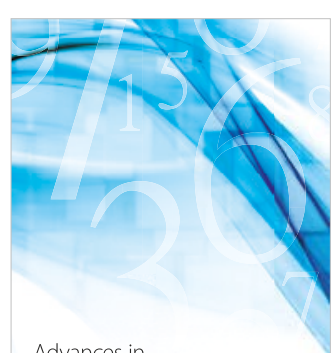

Advances in
Numerical Analysis
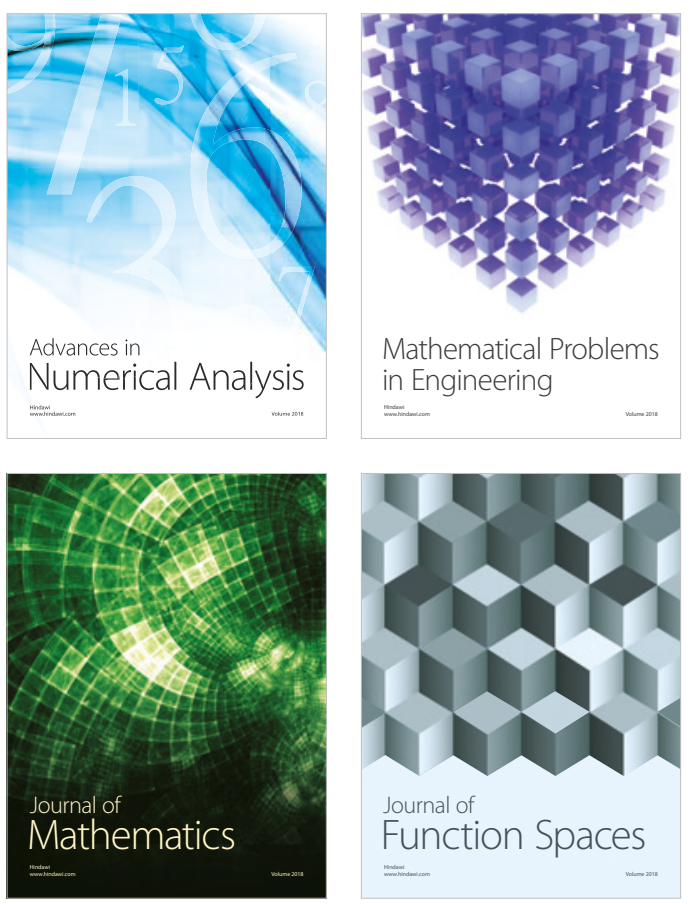

Mathematical Problems in Engineering

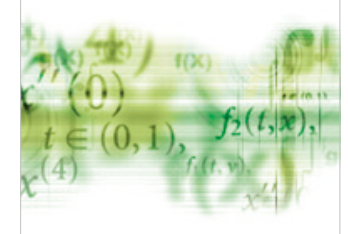

International Journal of

Differential Equations

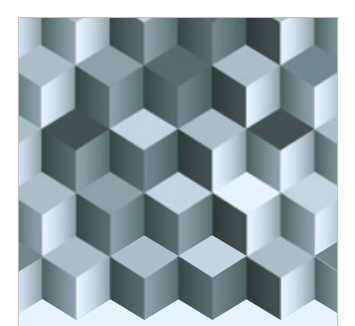

Journal of

Function Spaces

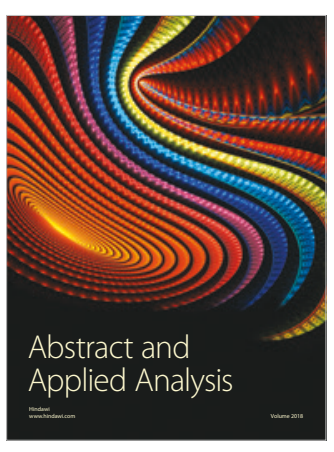

The Scientific

World Journal

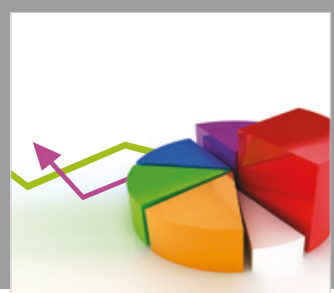

Journal of

Probability and Statistics
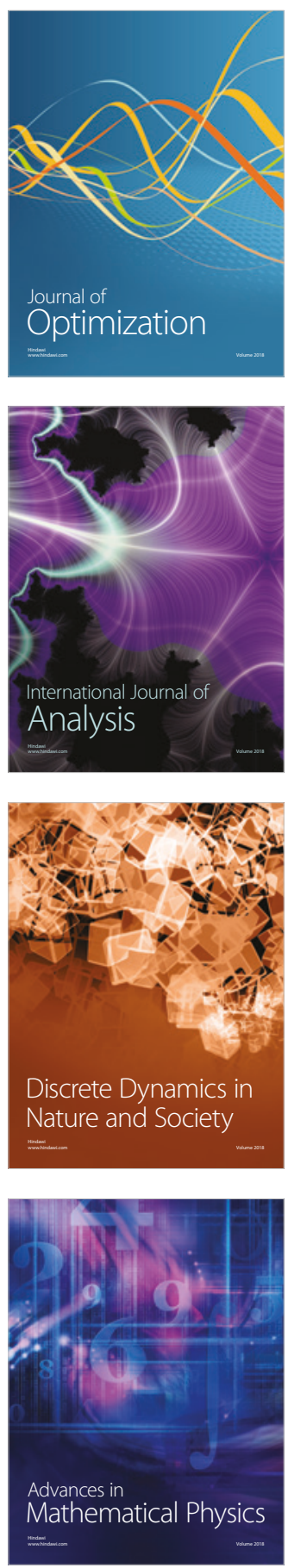